\title{
Use of Recycled Concrete Aggregates in Production of Green Cement-Based Concrete Composites: A Review
}

\author{
Natt Makul ${ }^{1}$, Roman Fediuk ${ }^{2} \oplus$, Mugahed Amran ${ }^{3,4, *}$, Abdullah M. Zeyad ${ }^{5} \oplus$, Gunasekaran Murali ${ }^{6}$,

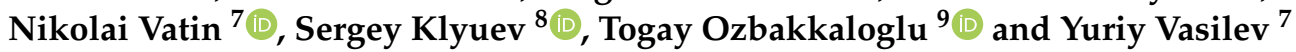

1 Department of Civil Engineering Technology, Faculty of Industrial Technology,

Phranakhon Rajabhat University, Bangkok 10220, Thailand; natt@pnru.ac.th

2 School of Engineering, Far Eastern Federal University, 8, Sukhanova Str., 690950 Vladivostok, Russia; roman44@yandex.ru

3 Department of Civil Engineering, College of Engineering, Prince Sattam Bin Abdulaziz University, Alkharj 11942, Saudi Arabia

4 Department of Civil Engineering, Faculty of Engineering and IT, Amran University, Amran 9677, Yemen

5 Department of Civil Engineering, Faculty of Engineering, Jazan University, Jazan 45142, Saudi Arabia; azmohsen@jazanu.edu.sa

6 School of Civil Engineering, SASTRA Deemed to Be University, Thanjavur, Tamil Nadu 613401, India; murali@civil.sastra.ac.in

7 Moscow Automobile and Road Construction University, 125319 Moscow, Russia; vatin@mail.ru (N.V.); yu.vasilev@madi.ru (Y.V.)

8 Department of Theoretical Mechanics and Strength of Materials, Belgorod State Technological University Named after V.G. Shukhov, 308012 Belgorod, Russia; klyuyev@yandex.ru

check for

updates

Citation: Makul, N.; Fediuk, R.; Amran, M.; Zeyad, A.M.; Murali, G.; Vatin, N.; Klyuev, S.; Ozbakkaloglu,

T.; Vasilev, Y. Use of Recycled

Concrete Aggregates in Production of Green Cement-Based Concrete Composites: A Review. Crystals 2021, 11, 232. https://doi.org/10.3390/ cryst11030232

Academic Editor: Cesare Signorini

Received: 9 February 2021

Accepted: 24 February 2021

Published: 26 February 2021

Publisher's Note: MDPI stays neutral with regard to jurisdictional claims in published maps and institutional affiliations.

Copyright: (c) 2021 by the authors. Licensee MDPI, Basel, Switzerland. This article is an open access article distributed under the terms and conditions of the Creative Commons Attribution (CC BY) license (https:/ / creativecommons.org/licenses/by/ $4.0 /)$.
9 Ingram School of Engineering, Texas State University, San Marcos, TX 78666, USA; togay.oz@txstate.edu

* Correspondence: m.amran@psau.edu.sa or mugahed_amran@hotmail.com

\begin{abstract}
Recycled concrete aggregates (RCA) are used in existing green building composites to promote the environmental preservation of natural coarse aggregates (NCA). Besides, the use of RCA leads to potential solutions to the social and economic problems caused by concrete waste. It is found that insufficient information on the longevity and sustainability of RCA production is a serious issue that requires close attention due to its impact on changing aspects of the sector. However, more attention has been paid to explaining the effect of RCA on concrete durability, as well as the properties of fresh and hardened concrete. Therefore, this study aims to provide a critical review on the RCAs for the production of high-performances concrete structures. It begins by reviewing the source, originality, types, prediction of service life, features and properties of RCA, as well as the effect of RCA on concrete performance. In addition, this literature review summarizes the research findings to produce complete insights into the potential applications of RCA as raw, renewable, and sustainable building materials for producing greener concrete composite towards industrializing ecofriendly buildings today. Further, it has also highlighted the differences in the current state of knowledge between RCAs and NCAs, and offers several future research suggestions. Through this critical and analytical study, it can be said that RCA has the possible use in the production of high-performance structural concrete depending on the source and type of recycled aggregate while the RCA can be used widely and safely to produce traditional green concrete.
\end{abstract}

Keywords: durability; hardened properties; green composite; fresh properties; recycled concrete aggregates; natural coarse aggregates

\section{Introduction}

One of the most Sustainable development is now a major development challenge for the entire world and has become the guiding standard for the construction sector [1]. Technological progress in the production of concrete and reinforced concrete requires additional sources of raw materials, in particular, the use of high-quality aggregates [2]. 
The implementation of this problem is impeded by the constantly growing shortage of mineral and energy resources, as well as environmental requirements for environmental protection [3]. Therefore, at present, the task is to comprehensively use the deposits of low-quality raw materials and waste from related industries [4].

Reusing and recycling concrete waste can be a successful strategy for achieving sustainability along the way [5]. Waste concrete is collected and crushed and then used in structural concrete, in which it replaces natural coarse aggregates (NCA) [6]. Many administrations worldwide have introduced various control measures to minimize the use of virgin aggregate and improve the recycling of concrete waste for reuse as materials when environmentally, technically, and economically acceptable [7]. Environmental problems are known to be exacerbated by rising landfill fees and land scarcity. The use of concrete waste in sustainable development can alleviate such problems [8]. However, it has been observed that most concrete plants were reluctant to produce recycled concrete aggregates (RCAs) and make full use of them [9]. Manufacturing plants have not yet mastered RCA's use, not only due to its unclear characteristics for concrete but also due to unexplored manufacturing processes, which, however, have yet to be determined [10]. It has been observed that most concrete batching plants are hesitant to manufacture and use RCA at their optimum [11]. However, it has become necessary to study this problem.

As a result of human-made and natural anomalies occurring on the Earth, there are many destroyed cities, settlements, and houses (see Figure 1 that shows the process of destroyed buildings wastes production as RCAs). The question is how to rebuild these cities and how to use parts of the destroyed buildings and structures [12]. One of the ways is to take everything out to relatively low forms of the earth's surface, store it, cover it with soil, plant a forest on top, produce new building materials and from them rebuild cities and settlements [13].

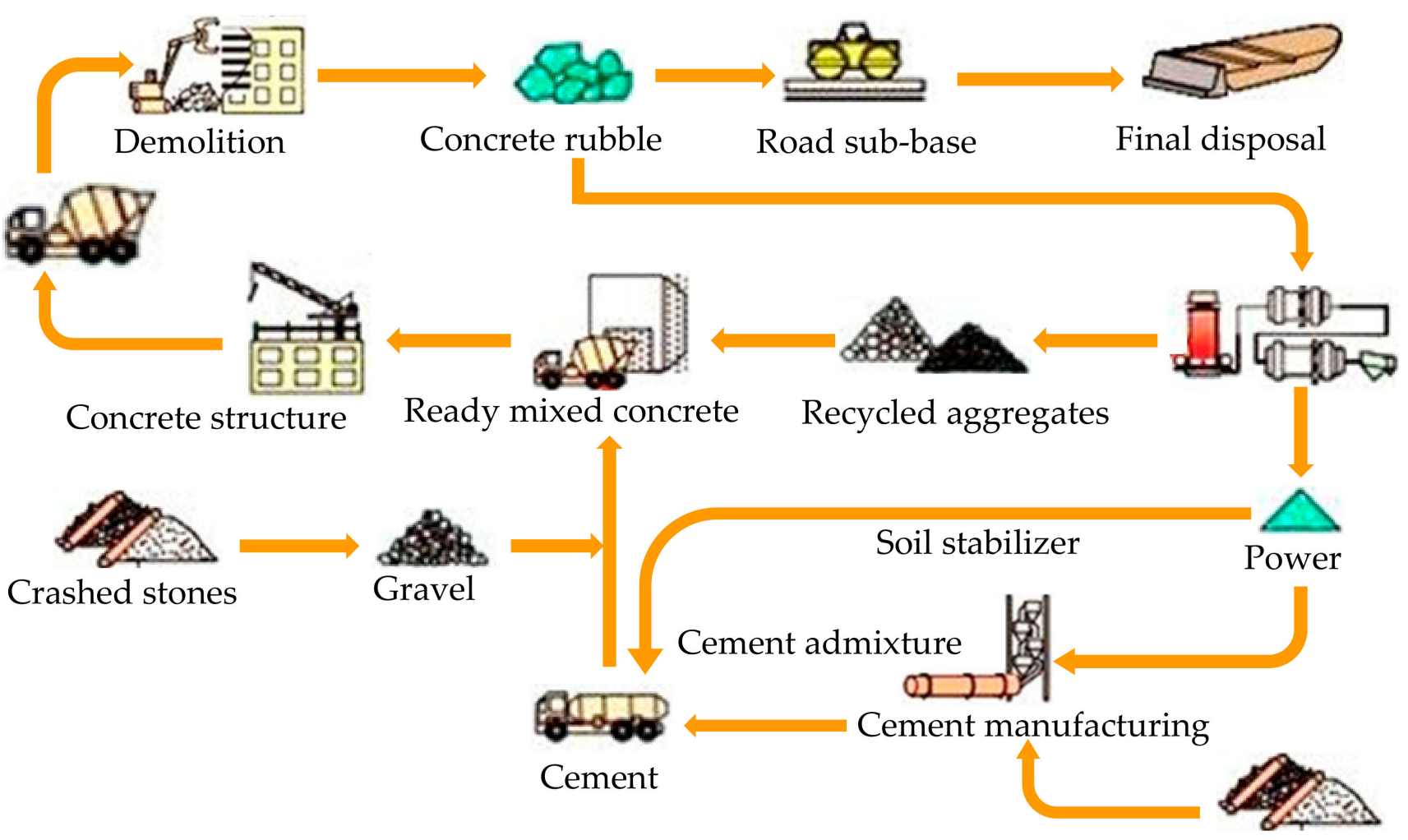

Cement (Clinker) raw materials

Figure 1. Process of destroyed buildings wastes production as RCAs. 
But this is a very expensive undertaking [5]. The second way out of this situation is the use of fragments of destroyed buildings and structures to create building materials, using which to repair and build new buildings and structures in place of the destroyed ones [14]. Demolition of old buildings and construction of new ones is common practice due to natural disasters, expansion of traffic routes, urban redevelopment, structural destruction and change of purpose [15]. In the European Union, about 850 tons of construction waste is generated annually, which is about $30 \%$ of the total waste [16]. Debris from demolition alone is about 123 tons annually in the United States [17].

Huge concrete waste is generated during the demolition of old buildings; then, it is most often disposed of in landfills, which poses significant health risks and damages the environment [18]. More than forty years ago, research began on the characteristics of RCA [19]. In the past, most of the research carried out was mainly limited to the production of unstructured concrete due to the deleterious physical properties of RCA, for example, high water absorption, which increases the need for water for a certain workability (Table 1) [20-22].

Insufficient information on the longevity and sustainability of RCA production is a serious issue that requires close attention due to its impact on changing aspects of the sector [23]. It is unknown whether the manufacturing, quality control, and production costs in standard RCA manufacturing industries outweigh the benefits from RCAs purchased as concrete components at a lower cost than natural concrete aggregates [24]. One explanation for the slow acceptability of production for RCA production is the already existing plants for the production of bulk ready-mixed concrete [25].

However, the current models, in which RCA increasingly replaces NCA in various structural designs, have gradually gained in importance for specific reasons [26]. For example, RCA manufacturing provides sustainability for concrete waste and encourages recycling rather than landfill [27]. In addition, it focuses on the lack of natural aggregates, minimizes the need for them, and ultimately allows the preservation of the NCA natural aggregates mined in the open pit [28]. Despite the cost, these and many other benefits have led to increased interest in manufacturing and using RCA in design [29,30]. It is found that insufficient information on the longevity and sustainability of RCA production is a serious issue that requires close attention due to its impact on changing aspects of the sector. Therefore, this study aims to provide a critical overview on the RCAs for the production of high-performances concrete structures. This study reviews the source, originality, types, service life prediction, features and properties of RCA. However, more attention has been paid to explaining the effect of RCA on concrete durability, as well as the properties of fresh and hardened concretes. In addition, this literature review summarizes the research findings to produce complete insights into the potential applications of RCA as raw, renewable and sustainable building materials for producing greener concrete composite towards industrializing ecofriendly buildings today. The paper evaluates high performance concrete structures that favor RCA's manufacturing activities rather than natural materials [31,32]. Therefore, it has also been highlighted the differences in the current state of knowledge between RCAs and NCAs, and offers some suggestions for future research. 
Table 1. Approval criteria about RCAs.

\begin{tabular}{|c|c|c|c|c|c|}
\hline Country & Standard & $\begin{array}{l}\text { Criterion of Oven-Dry } \\
\text { Density }\left(\mathrm{kg} / \mathrm{m}^{3}\right)\end{array}$ & RCA Type & $\begin{array}{l}\text { Absorption Ratio of the } \\
\text { Criterion of Aggregate (\%) }\end{array}$ & Refs. \\
\hline \multirow{3}{*}{ Australia } & \multirow{3}{*}{ AS1141.6.2 } & $\geq 2100$ & Class 1A & $\leq 6$ & \multirow{3}{*}[33]{} \\
\hline & & $\geq 1800$ & Class 1B & $\leq 8$ & \\
\hline & & $\geq 1500$ & Type 1 & No limit & \\
\hline \multirow{3}{*}{ Germany } & \multirow{3}{*}{ DIN 4226-100 } & $\geq 1800$ & Type 2 & $\leq 20$ & \multirow{3}{*}{ [34] } \\
\hline & & $\geq 2000$ & Type 3 & $\leq 15$ & \\
\hline & & $\geq 2000$ & Type 4 & $\leq 10$ & \\
\hline \multirow[t]{2}{*}{ Hong Kong } & \multirow{3}{*}{$\begin{array}{l}\text { Works Bureau of } \\
\text { Hong Kong }\end{array}$} & $\geq 2000$ & HK, 2000 & $\leq 10$ & \multirow[t]{2}{*}{ [34] } \\
\hline & & $\geq 2500$ & Fine-Class H & $\leq 3.5$ & \\
\hline \multirow{5}{*}{ Japan } & & $\geq 2200$ & Fine-Class M & $\leq 7$ & \multirow{5}{*}{ [35] } \\
\hline & \multirow{4}{*}{$\begin{array}{l}\text { JIS A } 5021,5022 \\
\text { and } 5023\end{array}$} & $\geq 2300$ & Coarse-Class M & $\leq 5$ & \\
\hline & & $\geq 2500$ & Coarse-Class H & $\leq 3$ & \\
\hline & & No limit & Fine-Class L & $\leq 13$ & \\
\hline & & No limit & Coarse-Class L & $\leq 7$ & \\
\hline \multirow{3}{*}{ Korea } & \multirow{3}{*}{ KS F 2573} & $\geq 2200$ & Fine & $\leq 5$ & \multirow{3}{*}{ [36] } \\
\hline & & $\geq 2500$ & Coarse & $\leq 3$ & \\
\hline & & $\geq 2000$ & Type 2 & $\leq 10$ & \\
\hline \multirow[t]{2}{*}{ International } & \multirow[t]{2}{*}{ RILEM } & $\geq 1500$ & Type 1 & $\leq 20$ & \multirow[t]{2}{*}{ [37] } \\
\hline & & $\geq 2000$ & - & $\leq 5$ & \\
\hline Spain & EHE & $\geq 2500$ & Type 3 & $\leq 3$ & [38] \\
\hline
\end{tabular}

\section{Source and Originality of RCA}

RCA originate from the Portland cement concrete demolition. Aggregate pieces can be expected to vary considerably, given that the original concrete could be weathered or fresh, loose or dense, weak or strong [39]. In the process of crushing, agglomerates of concrete aggregate with adhered mortar are formed [40]. Typically, these agglomerations are less efficient than angles units [41]. Fines are also formed from crushed concrete [42].

The aggregates form a concrete frame. Aggregates often take up about seventy percent of the total volume of concrete [43]. A large percentage of the number of these aggregates is mainly a coarse aggregate [44]. However, in the construction sector, the demand for coarse aggregate is enormous [45]. The growing extraction of raw materials from natural resources is essential to meet these high demands [46]. The ever-increasing use of natural large aggregates creates an ecological imbalance [47]. Therefore, the use of alternative raw materials is essential in the construction industry [48]. The use of RCA derived from demolished concrete buildings is one approach to achieving this goal [49]. The use of reclaimed concrete materials in structures minimizes the need for natural coarse aggregate [50]. In turn, this minimizes the negative environmental impacts due to natural aggregate recovery [51]. Rising landfill costs and NCA shortages have also contributed to the use of RCA in concrete [52]. In addition, the increased distances between the construction site and the NCA quality source have forced contractors to consider replacing the NCA with RCA [53]

The use of RCA in high performance and high strength structural concrete is possible due to proper quality control and mixing, and the addition of pozzolanic additives. It has been noted that poverty imposes specific constraints that lead to delays and sometimes a lack of programs to carry out various engineering processes [54]. Cost issues are limited by the difficulty of implementing environmentally friendly and sufficient, safe solutions such as aggregate recycling. In particular, front-loading and top-hopper industries can be used to reduce additional RCA costs [55]. However, pricing and the supply and demand aspects of recycled materials pose various challenges that are rarely considered.

In addition, it is necessary to carefully study the characteristics of concrete with each type of RCA [56]. In particular, the strength of concrete is influenced by various elements such as the replacement rate, moisture content, RCA type, and water-to-cement 
ratio [57]. Unlike natural aggregates, RCA generally has a higher water absorption, which can significantly affect concrete properties, especially workability [58]. In addition, concrete with drier RCA had a higher slump and more rapid slump flow than water-saturated concrete [59]. It is clear that the strengths for completely replacing fine aggregate increase over time, and blends having a higher percentage of the combination get better composite performance [60]. This reflects the characteristics of the presence of reclaimed concrete, which from the available literature review show that the strength of the material increases with the life of the structure [61]. The only reliable way to minimize construction costs is to use available local resources and introduce innovative building materials [62]. The use of RCA as fine aggregates in concrete seems to be the best, especially in areas where demolition waste is freely available [63].

\section{Service Life Prediction of RCA Concrete}

The theoretical basis for the design of green composites using the specified raw materials is the transdisciplinary science of geomimetics [64-66], which uses the results of studies of natural processes to create high-strength concretes and building composites of a new generation. The results were tested on raw materials from destroyed buildings and structures in Iraq, which mainly consist of concrete, ceramic bricks, and limestone wall blocks. The performance of RCA concrete is influenced by various key aspects such as air entrainment, cement content, curing conditions, RCA humidity conditions, properties of the original RCA concretes, RCA physical characteristics, RCA size and type, RCA content, and water to cement ratio [67]. The aspects are explained below.

\subsection{RCA Features and Percentage}

The physical properties of RCA have a significant effect on the properties of fresh and hardened concrete. For example, fresh concrete with coarse and angular particles becomes tough and therefore difficult to cast [68]. In addition, high RCA absorption can affect the workability of concrete. In addition, large RCA pore volumes can affect the durability characteristics (permeability and water absorption), strength, and porosity of concrete.

The fresh and hardened properties of concrete are strongly influenced by the RCA percentage used as a complete or partial replacement for NCA. Using seven independent variables, [69] created a model of aggregate quantity and type to predict concrete performance when replacing $0.0-100 \%$ NCA with RCA. The researchers reported that concretes created using RCA had a lower modulus and compressive strength than NCA concretes. Higher RCA content also increases water absorption but decreases density, resulting in increased concrete porosity. The use of coarse RCA reduces concrete density by $50-100 \%$ and increases water absorption by about $2.11 \%$ to $3.50 \%$ and from $0.14 \%$ to $0.38 \%$, respectively. In addition, it is noted that as the content of grounded RCA increases, the resistance to chloride ion penetration decreases, while the tensile splitting and compressive strength of concrete decreases [70]. In addition, the researchers noted that concrete drying shrinkage improved with increasing RCA content. It can be controlled by lowering the water to cement ratio.

\subsection{RCA Sizes and Original Concrete Quality}

It is used three different aggregate sizes to evaluate the effect of RCA size on concrete properties [71]. A more significant reduction in modulus of elasticity was obtained for concretes prepared with smaller RCA dimensions. On the other hand, they reported that the strength increases with the size of the RCA. In addition, they found that the water absorption of concrete decreases with increasing RCA dimensions. This is due to the relatively low content of weak solutions adhered to the coarse aggregate. It is investigated the effect of base concrete quality on RCA concrete performance [72]. Scientists reported that RCA water absorption increases with the strength of the base concrete. This is due to the fact that for concretes with higher strength, higher cement content is required in principle; therefore, the amount of mortar adhering to the aggregate increases. Thus, 
adjustments to mix water content are necessary for newer concretes, including RCA made from older, harder concretes, to obtain the preferred workability. Porous RCAs affect the strength of RCA concrete. The proportional loss of tensile or compressive strength of new concretes due to the use of RCA is more significant when it is obtained from weaker old concretes than from strong old concretes [45].

\subsection{Influence of Cement Content and Water to Cement Ratio}

RCA concretes with high cement content are reported to be highly resistant to carbonation. It is found that higher cement content in RCA concrete results in a preferred compressive strength [73]. It is also found that the RCA tensile strength of concrete increases with increasing cement content in concrete [74]. The degradation of RCA concrete is related to the water to cement ratio used in the mix design. It is reported that compared to the original RCA concrete, RCA concretes require a higher cement content and a lower water-to-cement ratio to achieve a certain compressive strength [75]. The resistance of the NCA to melting and freezing at water to cement ratio of 0.290 was exceptionally high. But for RCA concrete, the same water-to-cement ratio does not provide suitable freeze-thaw resistance.

\subsection{Hydration of Cement in the Original Concrete}

It has been established that the composition of the crushing concrete scrap contains about $30 \%$ of non-hydrated Portland cement, which makes it possible to use it as an active microfiller in the production of multicomponent highly active binders [34]. Aggregate from the concrete scrap has a partial or solid shell on the surface of its grains from the cement paste of crushed concrete, actively influences the process of forming both the structural characteristics of the cement paste and the dense interfacial transition zone between them [76]. The structure of concrete composites is characterized by lower water absorption (up to 3-7\%) and the presence of rather small and uniform pores in size [77].

\subsection{Sources or Types of RCAs}

Several studies have been carried out to investigate the effect of sources or types of RCA on concrete performance [78-80]. With the exception of concretes made from recycled aggregates made from masonry ceramics, which reported an increase in compressive strength, concretes made with coarse RCA had lower compressive strengths [81]. The modulus of elasticity of concrete has been reduced for all RCA types. However, RCAs made from red ceramics had a greater effect on reducing the modulus of concrete due to the lower density.

\subsection{Curing Conditions, RCA Moisture Conditions, and Air Entrainment}

External curing in the environment is more detrimental to RCA concretes than NCA ones. It is shown that the differences in splitting tensile strength among NCA and RCA concretes are large when they are hardened in the external environment [79]. In addition, It is found that the carbonization depth of RCA concrete water-cured is almost twice that of RCA air-cured concrete [73]. The decrease in carbonization depth caused by curing in water may be partly due to the higher internal moisture content of the concrete. The moisture conditions of the aggregate affect the workability of the concrete. The initial slump of concrete (workability measurements) is highly dependent on the initial free water content of the concrete mix. It is shown that although air-dry and saturated surface-dry RCA exhibit typical initial slump and slump loss, kiln-dried RCA results in faster slump losses and higher initial slump [79]. Thanks to the appropriate air entrainment, durable concrete can be obtained from RCA [82]. Air entrainment for NCA concretes is as successful as for RCA concretes [83]. In addition, the use of entrained air is more effective than reducing the water-to-cement ratio in increasing freeze- resistance of RCA concrete [84]. 


\section{Chemical Properties}

The chemical characteristics of RCA affect the performance of the concrete. The durability of concrete should be affected by the presence of reactive chemicals such as chlorides, alkalis and sulphates in RCAs. The chemical properties of RCA are summarized below.

\subsection{Soundness}

Soundness is an indicator of the stability of aggregates to environmental influences, such as atmospheric influences $[45,85-87]$. The strength test for magnesium sulfates and sodium sulfates is mainly used to assess the integrity of the aggregate. RCAs usually pass magnesium sulfate strength tests, but do not pass sodium sulfate strength tests. For RCA and NCA, respectively, the strength loss of magnesium sulfate were $70 \%$ and $2.50 \%$ [88]. These figures are identical to the results obtained by several researchers worldwide [45,85-87]. It is also examined the reliability tests of sodium sulfates and found that the losses were $12.0 \%$ and $9.0 \%$, respectively, for RCA and NCA [45,85-87]. Thus, the sodium sulfate leak test was in accordance with the standard. Moreover, the results are identical to those obtained by Lye et al. [87]. The failure of RCA is mainly associated with the distribution of pore sizes in aggregates.

\subsection{Reactivity of Alkali-Aggregates}

RCA concretes can undergo alkaline aggregate reactions (AAR) if the original concrete aggregate was prone to alkaline aggregate reactions. In addition, mortars adhered to RCA or the alkali content of the cement paste can have a significant impact on the AAR susceptibility of new concretes with RCA. The alkali content of RCA is related to the content of its solution. RCAs with more mortars lead to higher alkali content and are thus more susceptible to alkaline aggregate reactions.

\subsection{Sulfate and Chloride Content}

RCA can have high sulphate content due to sulphate substances present in adhered cement slurries. It is investigated the content of water-soluble sulfates for RCA and NCA [87]. The researchers set the sulfate content of $0.032 \mathrm{~g} / \mathrm{L}$ and $0.0250 \mathrm{~g} / \mathrm{L}$ for RCA and NCA, respectively. The sulfate content of RCA depends on the amount of adhered mortar/cement paste. Higher sulfate content in RCA indicates that higher amounts of mortar will attach to RCA.

High levels of chlorides have been found in RCA, formed from bases with prolonged exposure to chloride-oriented antifreeze agents. RCA with higher chloride content can affect the durability of new concrete due to corrosion of the steel reinforcement [45,85-87]. Since increased corrosion of steel can lead to premature failure of reinforced concrete structures, RCA made from old concrete with chloride content higher than $0.04 \mathrm{~kg} / \mathrm{m}^{3}$ should not be used in new concrete. Furthermore, polymer materials, rubbers, plastics, joint seals, textiles, wood, and paper can be present in RCAs [45,85-87]. In concrete, these materials become unbalanced when thawed, dried.

\section{Physical Properties}

The concrete properties and mix proportions are influenced by the physical properties of the RCA. Basic properties such as absorption, pore volume, bulk density, specific gravity, texture and shape of RCA are generally inferior to those of natural aggregate due to impurities and the presence of residual slurry/paste [87]. The magnitude of the impact will vary depending on the amount and nature of the recycled slurries or pastes present in RCA. From the available literature [89-91], a summary of the main physical characteristics of RCA is shown in Table 2. 
Table 2. Fundamental physical properties of NCA and RCA [67-69].

\begin{tabular}{ccc}
\hline Physical Properties & NCA & RCA \\
\hline Pore Volumes (vol.\%) & $0.50-2$ & $5-16.5$ \\
Absorptions (wt.\%) & $0.50-4$ & $3-12$ \\
Compacted Bulk Densities $\left(\mathrm{kg} / \mathrm{m}^{3}\right)$ & $1450.00-1750$ & $1200-1425$ \\
Specific Gravity & $2.40-2.90$ & $2.10-2.50$ \\
Shapes and Textures & Smooth and well rounded & Angular with rough surfaces \\
\hline
\end{tabular}

\subsection{Particle Size Distribution}

At present, during the development of fragments of destroyed buildings and structures, a large amount of unfractionated crushing concrete waste with a size of 0-5 mm is formed $[67,92,93]$, the use of which in the production of concrete is difficult due to the presence of a significant amount of dusty fraction in their composition (Table 3). However, judging by the chemical composition, the fine fraction of concrete scrap can be used as an additional cementitious material [94]. The comminuted form of the particles, as well as the high content of silica and clinker minerals in them, will contribute to their high activity, which is confirmed by the studies of other authors [95-97]. RCA have very rough and angular due to the crumbling of the concrete and the presence of grout adhered to the original rough surfaces of the aggregate (Figure 2). Consequently, recycled concrete aggregate has better adhesion to the cement matrix than natural one. Depending on the size of the aggregates, RCA particles typically contain 30 to $60 \%$ of mortar. RCAs are identical in particle shape to crushed stones, but the types of grinding tools affect the gradation and other characteristics of fine concrete. Also, Figure 3 shows the fundamental components of demolition wastes [80].

Table 3. The mineral composition of various fractions of demolition wastes.

\begin{tabular}{ccccccc}
\hline \multirow{2}{*}{ Particle Sizes, $\mathbf{m m}$} & \multicolumn{7}{c}{ Mineral Composition, \% } \\
\cline { 2 - 7 } & $\mathbf{S i O}_{2}$ & $\mathbf{C a}(\mathbf{O H})_{2}$ & $\mathbf{C a C O}_{3}$ & $\mathbf{C S H}$ & $\mathbf{C}_{3} \mathbf{S}_{2}$ & $\mathbf{C}_{2} \mathbf{S}$ \\
\hline $0.00-0.16$ & 48.4 & 11.5 & 10.0 & 5.8 & 12.0 & 12.3 \\
$0.16-0.315$ & 55.2 & 7.4 & 11.0 & 4.4 & 11.0 & 11.0 \\
$0.315-0.63$ & 56.4 & 11.0 & 3.9 & 12.0 & 6.7 & 10.0 \\
$0.63-1.25$ & 65.1 & 12.0 & 6.0 & 5.9 & 5.0 & 6.0 \\
$1.25-2.5$ & 64.4 & 10.5 & 6.9 & 3.0 & 7.6 & 7.6 \\
$2.5-5$ & 62.8 & 11.0 & 0 & 6.0 & 9.2 & 11.0 \\
$5-20$ & 60.8 & 8.0 & 3.0 & 4.0 & 9.0 & 11.2 \\
$20-40$ & 56.0 & 11.4 & 3.0 & 12.9 & 6.7 & 10.0 \\
$40-70$ & 64.5 & 10.4 & 6.0 & 3.9 & 7.6 & 7.6 \\
\hline
\end{tabular}
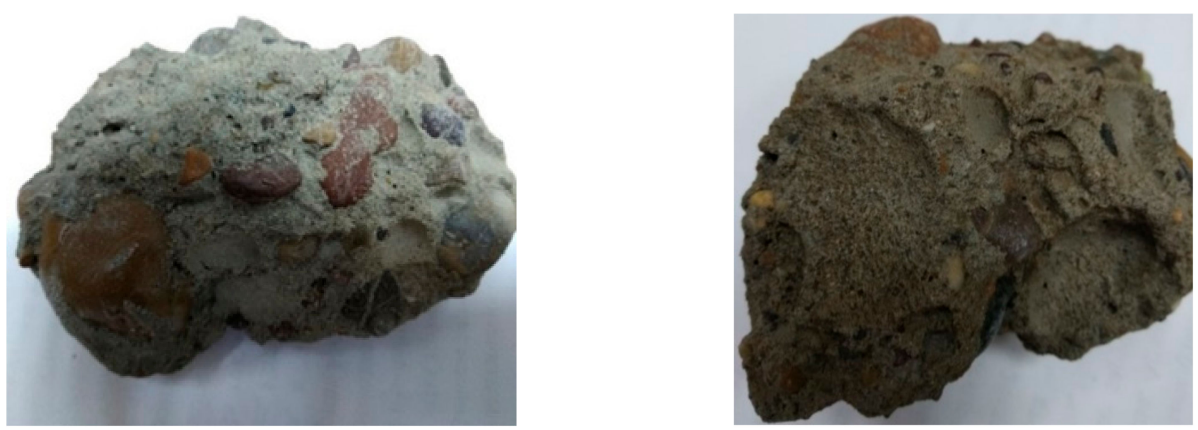

Figure 2. Original rough surfaces of the RCAs. 


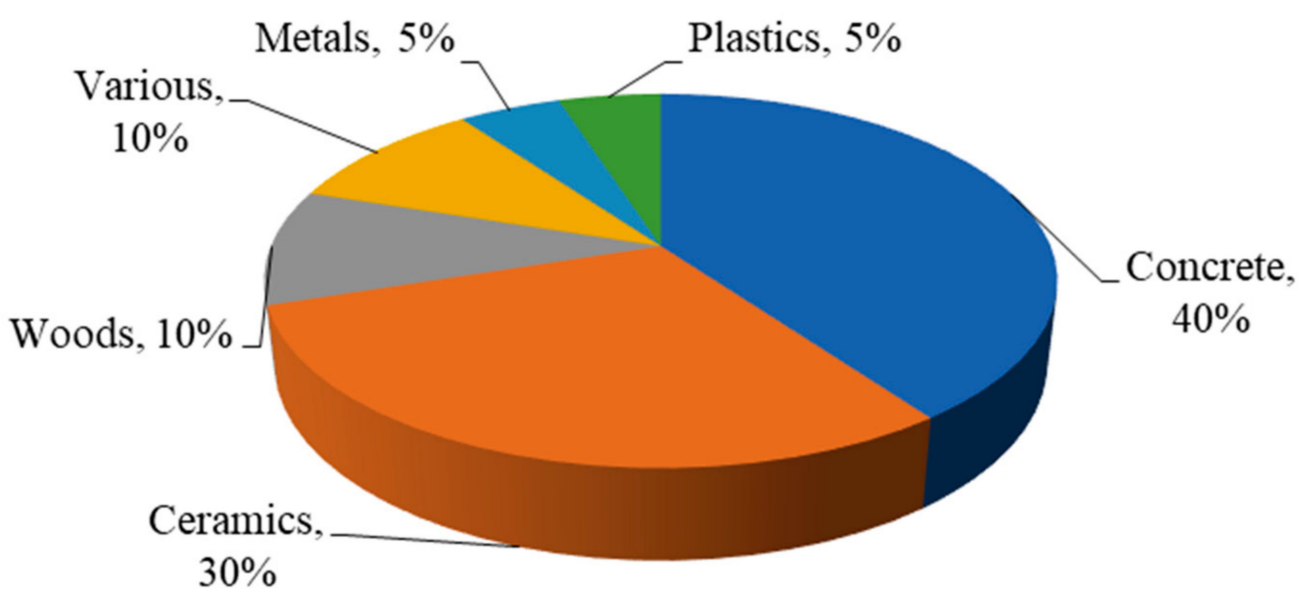

Figure 3. Fundamental components of demolition wastes [80]. Reprinted with permission from Elsevier [80].

\subsection{Specific Gravity and Bulk Density}

The specific gravity and bulk density of RCA are often lower, and the pore volume and absorption, respectively, are higher than those of natural aggregate. The lower specific gravity of RCA is due to the presence of aggregate particles in the old cement mortar/paste, which makes it less dense than NCA due to its higher porosity [98]. In saturated dry conditions, RCA distinctive gravity ranges from 2.10 to 2.50 , which is $5-10 \%$ less than NCA as shown in Table 2. Experimental data from Aliabdo et al. [99] found that RCA bulk densities are $9.80 \%$ less than primary gravel aggregates. Compared to virgin concrete aggregate, the higher pore volume of RCA makes it less dense and fragile.

\subsection{Aggregate Grounded, Abrasion and Effect Values}

Aggregate ground values (AGV) are measures of the aggregate resistance to commination under progressively applied compressive loads. It is reported that the lower the value, the stronger the aggregates. It was found that ACV for NCA (14\% to $22 \%)$ is significantly less than for ACV for RCA (20-30\%) from the literature [54,100-102] and as indicated in Table 3. This is expected due to the relatively weak mortars and cement pastes attached to the RCA particles.

The aggregate abrasion values (AAV) are a measure of the aggregate wear resistance. When material loss due to wear becomes higher, a higher AAV is obtained. Generally, the cumulative abrasion of RCA is higher than NCA. Classic RCA values range from $20 \%$ to $45 \%$, which is higher than the values for pure concrete aggregates, as shown in Table 3 [54,100-102]. Despite its origins, RCA's cumulative abrasion rates are nevertheless generally below the acceptable optimum limits for structural applications ( $50 \%$ by weight).

Furthermore, aggregate effect values (AEV) are the aggregate strength values exposed to impact. AEVs indicate the aggregate resistance to dynamic loads. As shown in Table 4, AEV of NCA ( $15 \%$ to $20 \%$ ) are lower than RCA (20\% to 25\%) [54,100-102]. Attached cementitious and mortar pastes make RCA less durable and thus lead to higher toughness values for RCAs that were frozen or wetted. About $0.150 \%$ by weight RCA is the acceptable limit for organic matter.

Table 4. The main RCA and NCA mechanical properties [54,100-102].

\begin{tabular}{ccc}
\hline Mechanical Properties (wt. $\%$ ) & RCA & NCA \\
\hline Aggregate Grounded Values & $20-30$ & $14-22$ \\
Aggregate Abrasion Values & $20-25$ & $15-30$ \\
Aggregate Effect Values & $20-25$ & $15-20$ \\
\hline
\end{tabular}




\section{Fresh Properties}

RCA can affect the performance of fresh concrete due to their higher porosity, absorption, surface roughness, and angularity [103]. The higher size and angularity of RCAs will reduce the workability of the concrete and make it difficult to lay it properly [104].

\subsection{Workability}

Workability decline rates increase with the improvement in the proportion of RCA in concrete mixes [105]. Thus, RCA concretes require more water to obtain similar workability to NCA concretes [106]. Concrete mixes that integrate RCA generally meet the initial settlement requirements [107]. Also, Table 5 summaries the RCA effects on the concrete hardened features. However, greater RCA uptake can lead to a rapid loss of workability, which limits the time required for paving and completing concreting [108]. Problems associated with rapid loss of workability should be addressed by changing and controlling the RCA water content before mixing or increasing the amount of superplasticizer, rather than adding more water on construction sites [109]. In general, the greater sharpness and surface coarseness of RCA particles reduce the concrete workability and lead it more problematic to finish appropriately.

Table 5. The RCA effects on the concrete hardened features $[7,110,111]$.

\begin{tabular}{cc}
\hline Properties & Comparison with NCA Concrete \\
\hline Thermal Expansions & $10-30 \%$ more \\
Creeps & $30-60 \%$ more \\
Drying Shrinkages & $20-50 \%$ more \\
Penetrations of Chlorides & $0-30 \%$ more \\
Water Absorptions & $0-40 \%$ more \\
Permeability & $0-50 \%$ more \\
Porosities & $10-30 \%$ more \\
Elasticity Modulus & $10-45 \%$ more \\
Strength of Bonds & $9-19 \%$ less \\
Flexural Strengths & $0-10 \%$ less \\
Splitting Tensile Strengths & $0-10 \%$ less \\
Compressive Strengths & $0-30 \%$ less \\
Dry Densities & $5-15 \%$ less \\
\hline
\end{tabular}

\subsection{Wet Density}

Several studies have been conducted to investigate the effect of RCA on the wet density of concrete [112]. Typically, the wet density of RCA concrete is lower than that of virgin concrete aggregates, as noted in Table $4[7,110,111]$. Compared to NCA concrete, it has been observed that the wet density of RCA concrete is $5-15 \%$ less [111]. This RCA contains adhered old cement pastes or mortars that are less dense than NCA [113]. As a rule, the density of hardened RCA concrete is $5-15 \%$ less than that of concrete with natural aggregates [114]. This is due to the used solutions attached to the RCA [115]. Depending on the size of the aggregate, the amount of mortar attached to the re-concrete aggregates ranges from $30 \%$ to $60 \%$ by volume RCA [116]. The density of the secondary mortar is much lower than that of most natural concrete materials [117]. This results in a lower density of RCA concrete [118].

\subsection{Stability}

The stability of the concrete mix enhanced as a result of abridged bleeding and augmented cohesiveness. Therefore, the resistance to segregation of NCA concrete could be equivalent to that of RCA concrete. As a rule, the soaking of NCA concrete is greater than that of RCA concrete [6]. During mixing, some of the ancient cement pastes are wiped off the RCAs and form additional fines in the concrete mix. Thus, these fine particles minimize the soaking of the concrete after some water has been adsorbed in the mixture. With lower free water content, more fine particles also increase the adhesion of the concrete 
mix. In addition, the increased surface roughness and angularity at higher RCA levels contribute to better concrete adhesion. The stability of the concrete mix is enhanced by improved cohesiveness and minimal soaking [119].

\subsection{Air Content}

The air content in concrete is significantly affected by the volume of their mortars. RCA influences the air content of concretes as they have higher mortar content. Fresh concrete having RCA is usually $60 \%$ more than the air content of fresh NCA concrete [62]. This is due to air entrained in recycled RCA mortars. Thus, when determining the target air content in RCA concrete, the existing air content in the mortar must be taken into account.

\section{Mechanical Properties}

The mechanical properties of concrete depend on the properties of the aggregate. It was found that the mechanical characteristics of RCA are lower in comparison with the mechanical characteristics of primary concrete aggregates from the available literature $[87,98,99]$. The main mechanical characteristics of RCA and NCA are listed in Table 3 and then briefly explained [120-122].

\subsection{Compressive Strength}

Silva et al. [123] studied the effect of adding a small percentage of waste plastic fiber and waste building material on some of the mechanical properties of concrete. In his study, the volume fraction of waste was $0.1-0.2 \%$ by volume. The results obtained proved the improvement in compressive and flexural strength. The results also showed an increase in the density of the fiber-reinforced concrete specimens compared to the control mix. As shown in Figure 4, the compressive strength of RCA concrete is often 5-10\% lower than that of virgin concrete [124].

* 3 days $\quad$ (5) 7 days 28 days

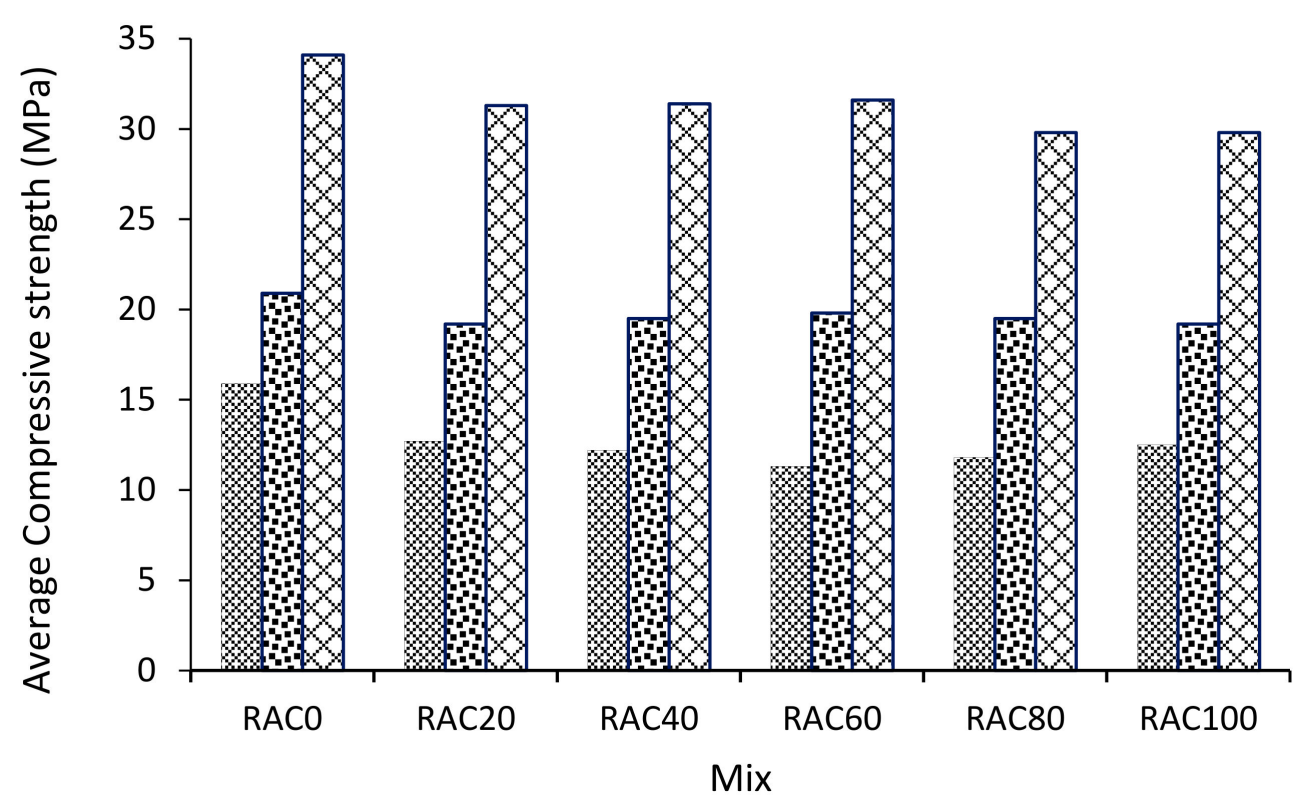

Figure 4. Compressive strength versus level of replacements of NCA by RCA [124]. Reprinted with permission from Elsevier [124].

Depending on the RCA quality, it can also be reduced by up to $25 \%$. Typically, higher air content in concrete mixes with RCA can also lead to lower strength values [99]. RCA concretes, however, can have the same and sometimes higher compressive strength than NCA concretes if the reclaimed concrete is obtained from old sources of concrete that were originally produced with a lower water to cement ratio than new concretes. 
Duan et al. [125] found that RCA does not have any effect on the compressive strength of concrete up to a degree of substitution of $30 \%$ by weight, after which it decreases. It is also showed that the compressive strength of concrete was much lower when RCA was used in dry state [87]. The reduction in compressive strength from $20 \%$ to $30 \%$ was realized due to the use of RCA in the case of high strength concretes. Similar results have been noted by other researchers $[87,98,126]$. Seethapathi et al. [127] studied the selfcompacting properties of concretes made with RCA and compared them with those of NCA concretes. Nitesh et al. [128] found that at the same age, the variation in compressive strength was negligible.

In addition, fine RCAs can affect the compressive strength of concrete. The compressive strength of RCA concrete depends on the ratio of the coarse aggregate to the fine aggregate of the original RCA concrete according to [129]. A lower ratio of coarse aggregate to fine aggregate results in more mortar adhered to the coarse RCA particles, and therefore a decrease in the strength of RCA concrete. This reduction is even greater when using recovered fines. Thus, the use of fine RCA in concrete is generally not recommended. Nevertheless, according to Maria et al. [130], the reduction in compressive strength did not occur for concretes containing up to $20 \%$ fine RCA. Strength decreases with increasing RCA content above this level.

The strength of RCA concrete can be increased either by soaking up a portion of the reconstituted aggregates for mixing without or with pozzolanic fluids during mixing, or by soaking RCA in mixtures of pozzolanic fluids such as colloidal silica or water before mixing the concrete. It is expected that microcracks in RCA will be filled with absorbed pozzolanic fluids or water absorbed cement gels during pozzolanic reactions or cement hydration. Consequently, the strength of RCA concrete can be increased.

\subsection{Splitting Tensile and Flexural Strengths}

There is limited literature on the effect of RCA on the tensile strength of concrete $[39,46,100]$. As shown in Figure 5 [124], tensile strength at cracking of RCA concrete is lower than that of NCA concrete. Various researchers have reported that the splitting tensile strength of RCA concrete is $0-10 \%$ less than that of NCA concrete $[39,46,100]$. Over a period from 90 to 365 days, there was no statistically significant decrease in tensile strength. Guo et al. [46], in contrast, noted that RCA concretes have higher tensile strength than NCA concretes. Therefore, more research is needed to investigate the effect of RCA on concrete cracking toughness.

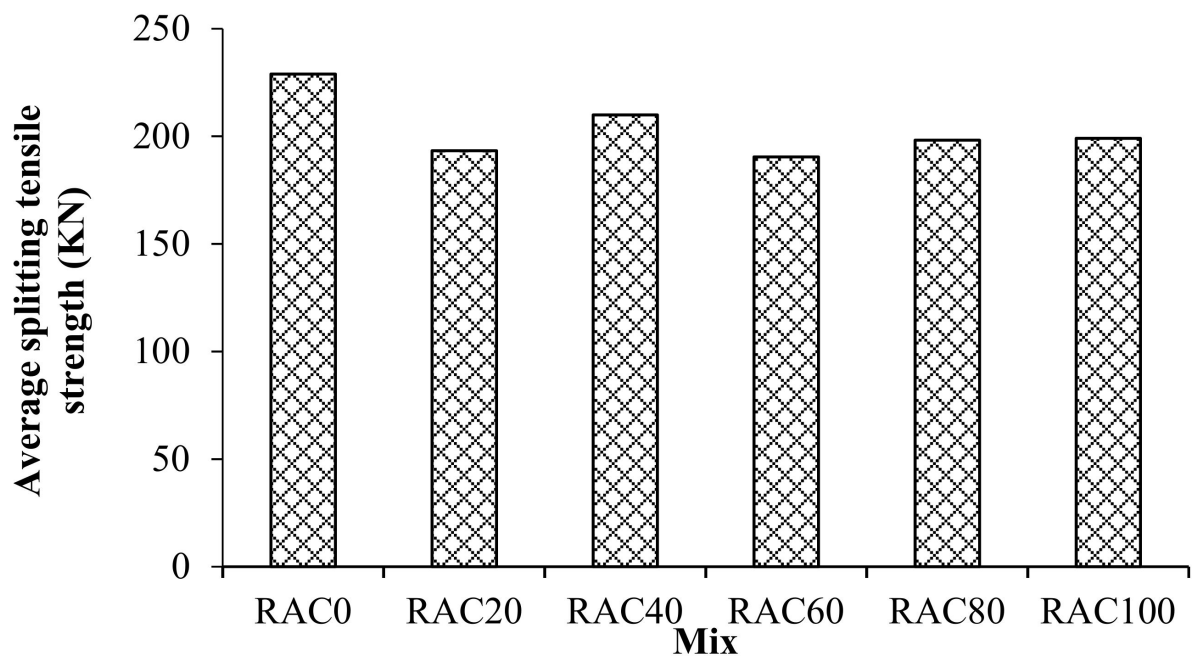

Figure 5. Splitting tensile strength versus level of replacement of NCA by RCA [124]. Reprinted with permission from Elsevier [124]. 
Typically, as shown in Figure 6, the flexural strength of RCA concrete is less than that of NCA concrete [124,131-133]. However, the flexural strength of 3 day RCA concrete was higher than that of NCA concrete, but at 28 days the strength was lower according to [131]. In their studies, NCA concrete gradually increased in strength and had greater flexural strength than RCA concrete at a later age. It is noted that RCA has never had a noticeable negative effect on the flexural strength of concrete [133]. However, given sufficient strength, RCA concretes can be produced for various purposes, sometimes even with $100 \%$ NCA replacements.

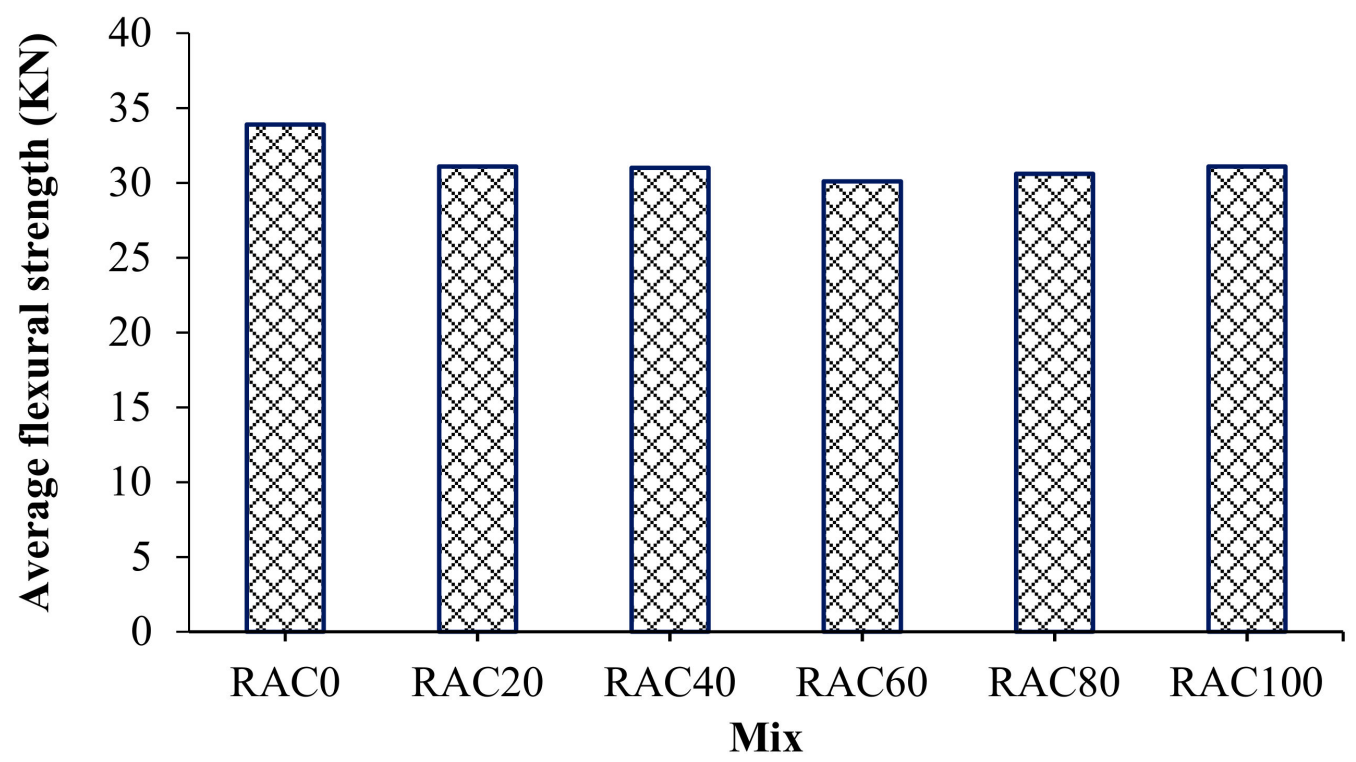

Figure 6. Flexural strength versus level of replacement of NCA by RCA [124]. Reprinted with permission from Elsevier [124].

\subsection{Bond Strength and Impact Strengths}

The bond strength of concrete is an indicator of the interrelated properties of pastes and aggregates. Rough RCA surfaces provide better adhesion than pure concrete aggregates. To test the bonds between reinforcement and concrete, which included $100 \%, 50 \%$ and $0 \%$ RCA, in [134], cylindrical specimens $150 \mathrm{~mm} \times \varnothing 100$ with fixed soft and ribbed reinforcement were used (diameter $=12 \mathrm{~mm}$ and embedment length $=150 \mathrm{~mm}$ ). The data obtained showed that RCA connections between reinforcement and concrete are not strongly influenced by RCA inclusions in concrete. It is, however, showed that the bond strength of NCA concrete was 9-19\% higher than that of RCA concrete [135]. These conflicting results mean more research is needed to investigate the effect of RCA on concrete bond strength.

The impact of RCA on the hardened concrete performance can be significant or negligible depending on their physical characteristics, grades, content, types and sources [136]. The performance of RCA hardened concrete declines with the NCA substitution rate due to reclaimed concrete aggregates [3]. Without significant effect on the properties of hardened concrete, up to $30 \mathrm{wt}$. \% natural filler can be replaced with RCA. As noted in the available literature, various changes in the performance of RCA hardened concrete are presented in Table 4.

\subsection{Elasticity Modulus}

The elasticity modulus of concrete is increased by an aggregate with a higher elasticity modulus. As shown in Figure 7, the elasticity modulus of concrete thus decreases with increasing RCA content in the concrete $[129,136,137]$. As a rule, the elasticity modulus of RCA concrete is $10-33 \%$ less than that of NCA concrete. It is demonstrated that the use of $30 \%$ RCA in concretes led to a decrease in the elasticity modulus by about $15 \%$ [129]. 
However, compared to NCA concrete, RCA concrete's elasticity modulus can be as low as $46 \%$. The decrease in the modulus of elasticity of concrete is due to the fact that RCA generally have a lower elasticity modulus compared to NCA. In addition, the decrease in the elasticity modulus of concrete is associated with an improved total content of mortars (recycled and new), which have lower elastic moduli than most concretes based on natural aggregates.

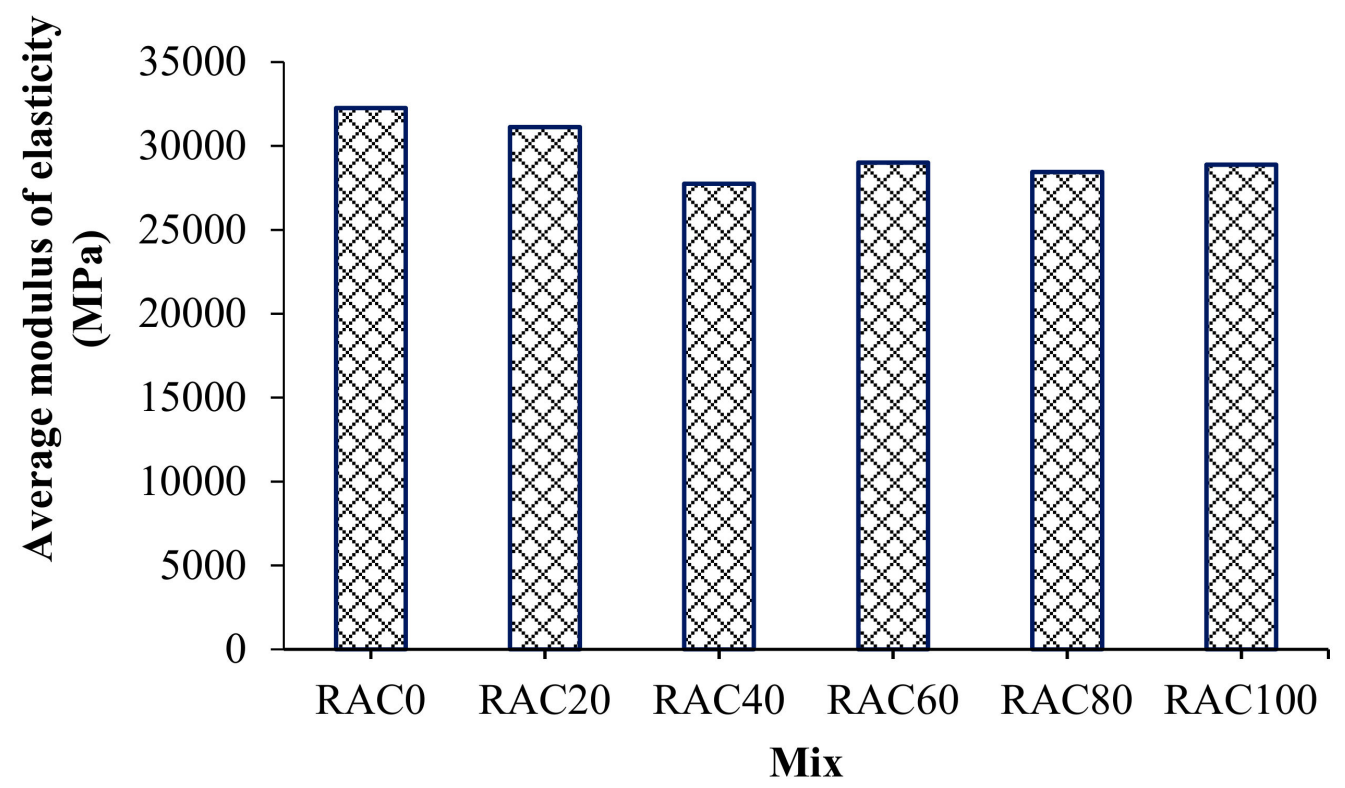

Figure 7. Modulus of elasticity versus level of replacement of NCA by RCA [124]. Reprinted with permission from Elsevier [124].

\subsection{Creep and Thermal Expansion}

Limited research has been done on the creep of RCA concrete. As a rule, the creep of RCA concrete is greater than the creep of NCA concrete $[76,86,87]$. This is because creep depends on the paste content, which can be $51 \%$ higher in RCA concretes.

Thermal expansion coefficients mainly depend on the content and types of aggregates. It is noted that the coefficients of thermal expansion of RCA concrete are usually $10-30 \%$ higher than that of NCA concrete [138]. However, further studies of the effect of RCA on the thermal expansion behavior of concrete are required to confirm these results.

\subsection{Drying Shrinkage}

Drying shrinkage commonly depends on the ratio of water to cement and paste content and is controlled by the aggregate particles. In some works, it was found that shrinkage is $20-50 \%$ higher than that of NCA concretes, because RCA concretes have a high paste content $[45,86,87,139]$. On the other hand, several studies have reported relatively lower RCA drying shrinkage values. It is reported low shrinkage strain at different curing ages of concrete when replacing 30\% virgin concrete aggregate with recycled concrete aggregate, as shown in Figure 8 [140]. Conflicting results suggest that more research is needed to investigate the effects of RCA on concrete shrinkage when drying. 


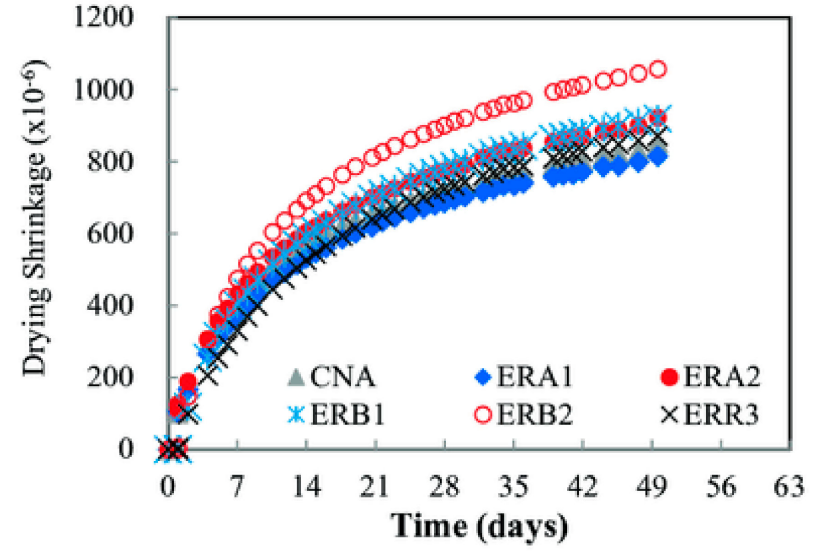

(a)

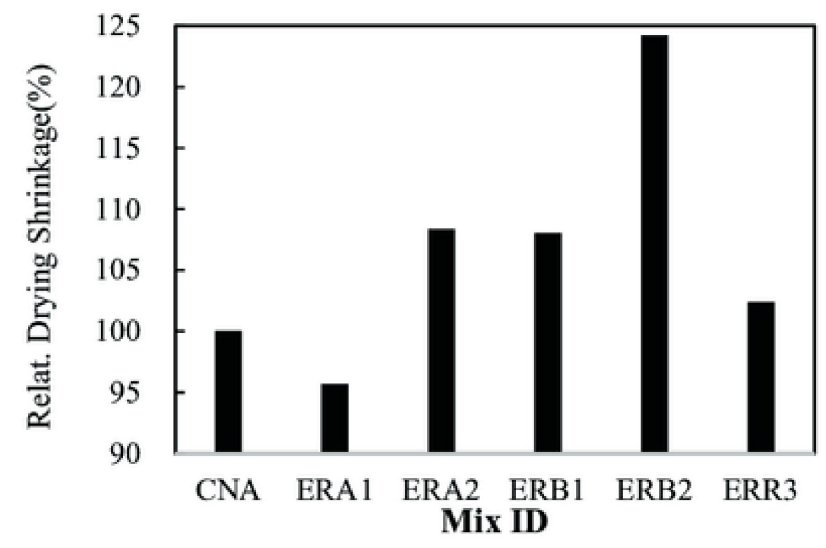

(b)

Figure 8. (a) Drying shrinkage versus time of exposure, and (b) drying shrinkage versus type of mix (ID) [140]. Reprinted with permission from MDPI [140].

\section{Durability and Functional Properties}

Concrete's ability to resist abrasion, chemical attack, weathering, and other adverse operating conditions is durability. Even when RCA is constructed from concretes with strength problems, RCA concretes can be significantly durable, provided the quality is maintained during construction and the mix ratio is correct $[86,87,118,141]$. The various strength characteristics of RCA concrete are described below.

\subsection{Permeability}

As shown in Figure 9, the porosity of the aggregate was less than that of the control concretes with aggregates from virgin concrete [55,142-144]. It is also reported that for all concretes the total porosity was increased at 50\% RCA [143]. However, at 100\% NCA substitution, class 20 concrete had a slightly lower porosity than traditional class 20 concrete. The porosity of RCA concrete can be 10-30\% higher than that of NCA concrete, depending on the strength class according to [142]. These characteristics of RCA concrete are due to differences in the composition of concrete mixes such as RCA and cement content, aggregate amount and percentage of pozzolan.
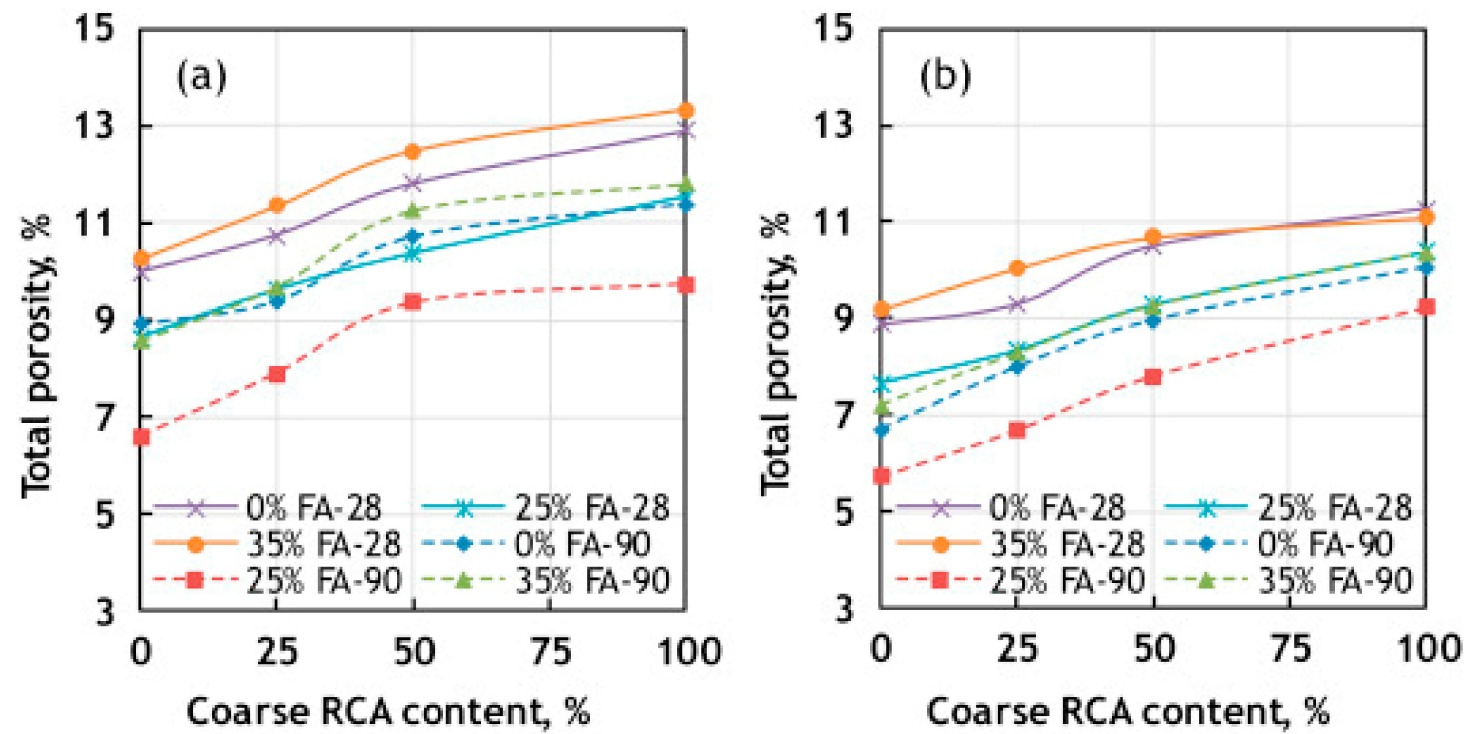

Figure 9. Total porosity versus level of replacement of NCA by RCA, with (a) Water/cement (w/c) ratio of 0.55 ; (b) w/c ratio of 0.45 [144]. Reprinted with permission from Elsevier [144]. 
The permeability of concrete depends both on the permeability of the concrete matrix (binder and cement paste) and on the absorptive capacity of the aggregate. In addition, the permeability of concrete is influenced by pore continuity, distribution, size, and porosity. The coefficients of intrinsic gas permeability of RAC are shown in Figure 10. The gas permeability of RAC decreased significantly with the carbonated RCAs; it is also showed an increase on the carbonation pressure from 0.1 Bar to 5.0 Bar still helped to reduce the gas permeability of RAC with new RCAs [72].

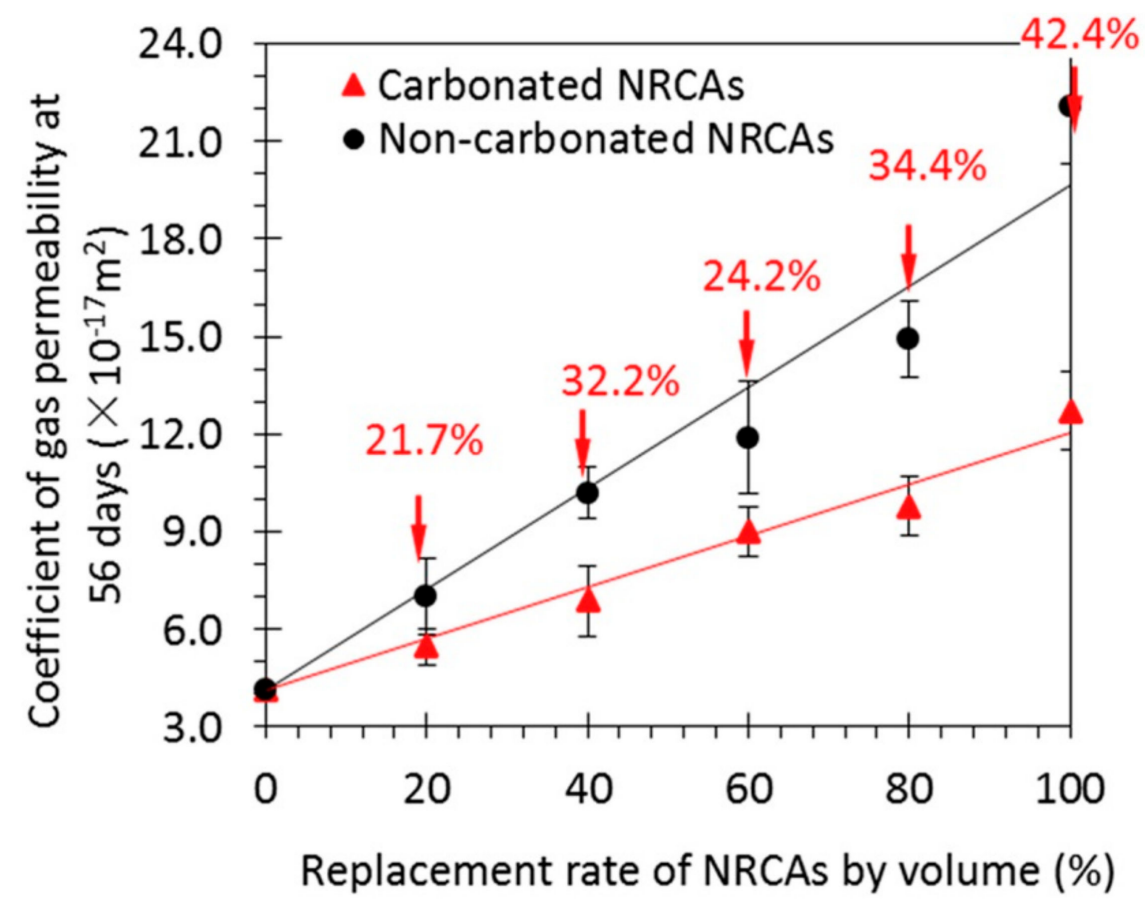

Figure 10. Gas permeability versus curing age [72]. Reprinted with permission from Elsevier [72].

\subsection{Water Absorption}

The water absorption of RCA concrete is expected to be greater than that of NCA one. This is due to the very high air permeability and water absorption of RCA. As shown in Figure 11, water absorption of concrete increased with increasing RCA content [145]. The water absorption of RCA concrete is $0-40 \%$ higher than that of NCA concrete, depending on the strength grades according to [146]. The author did not explain the reason for the lower water absorption at 20\% RCA content, but suggested further research.

\subsection{Sulfate and Chloride Resistance}

Limited research has shown that RCA concrete's sulfate resistance is about the same or slightly lower than that of natural concrete aggregates [147-149]. In general, the sulfate resistance of RCA concrete can be improved by using silica fumes, fly ash and fine-grained blast-furnace slags and using the correct mixing ratio. Good quality control of the construction and correct dosing of mixes can reduce the corrosion rate of steel reinforcement in RCA concretes. It is applied polarization approaches to determine the corrosion behavior of steel anchored in RCA concretes [148]. The researchers reported that the corrosion rate never depended on aggregates for lower chloride levels (0.50\%) and binder type. Compared to NCA concrete, the researchers also reported that RCA concrete with $65 \%$ fine blast furnace slag and $30 \%$ pulverized fuel ash was more successful in mitigating corrosion reactions at higher chloride levels. 


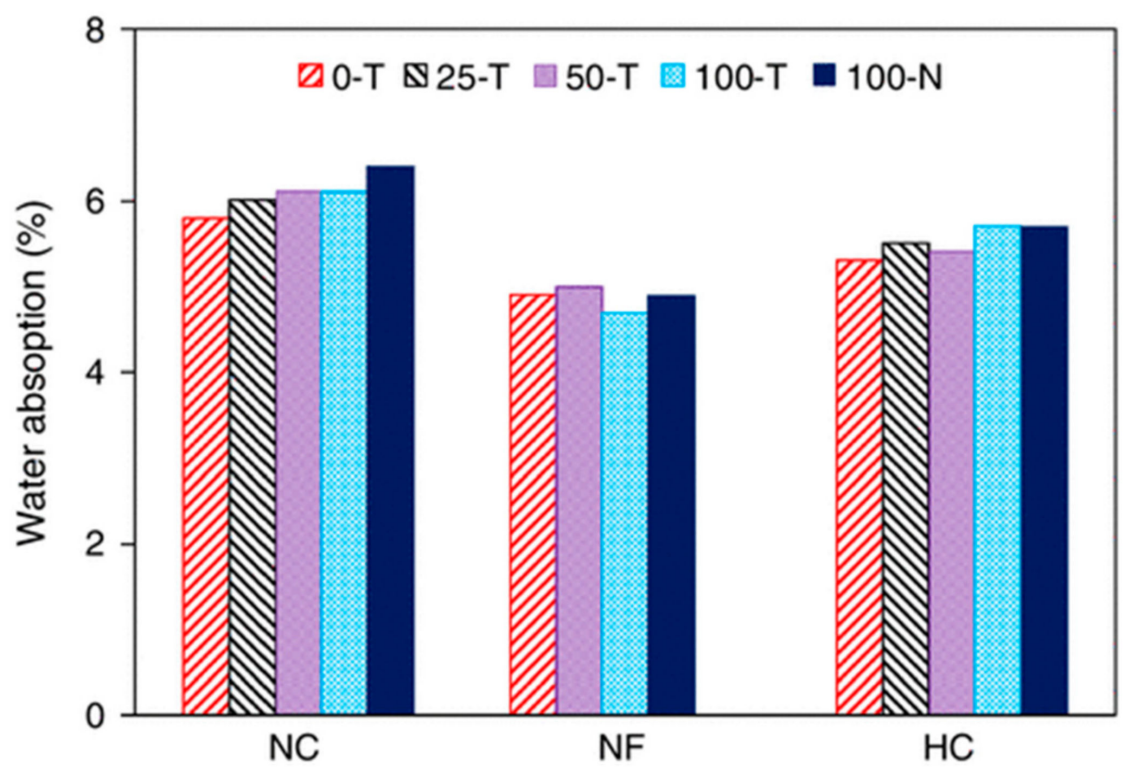

Figure 11. Water absorption versus level of replacement of NCA by RCA [145]. Reprinted with permission from Ozbakkaloglu et al. [145].

It is noted that the high chloride penetration rates in concrete made with and without RCA were very similar [139]. The use of $100 \%$ RCA in concretes reduces their ability to resist the penetration of chloride ions by about $30 \%$ compared to NCA concrete $[143,150]$. However, the chloride penetration resistance of RCA concrete can be significantly improved by increasing additional binders such as crushed granular blast furnace slag and fly ash. It is disclosed that, in comparison with fly ash, crushed granular blast furnace slag reduced the diffusion coefficient of chloride in concrete by about $80-200 \%[147,150,151]$ (See Figures 12 and 13).

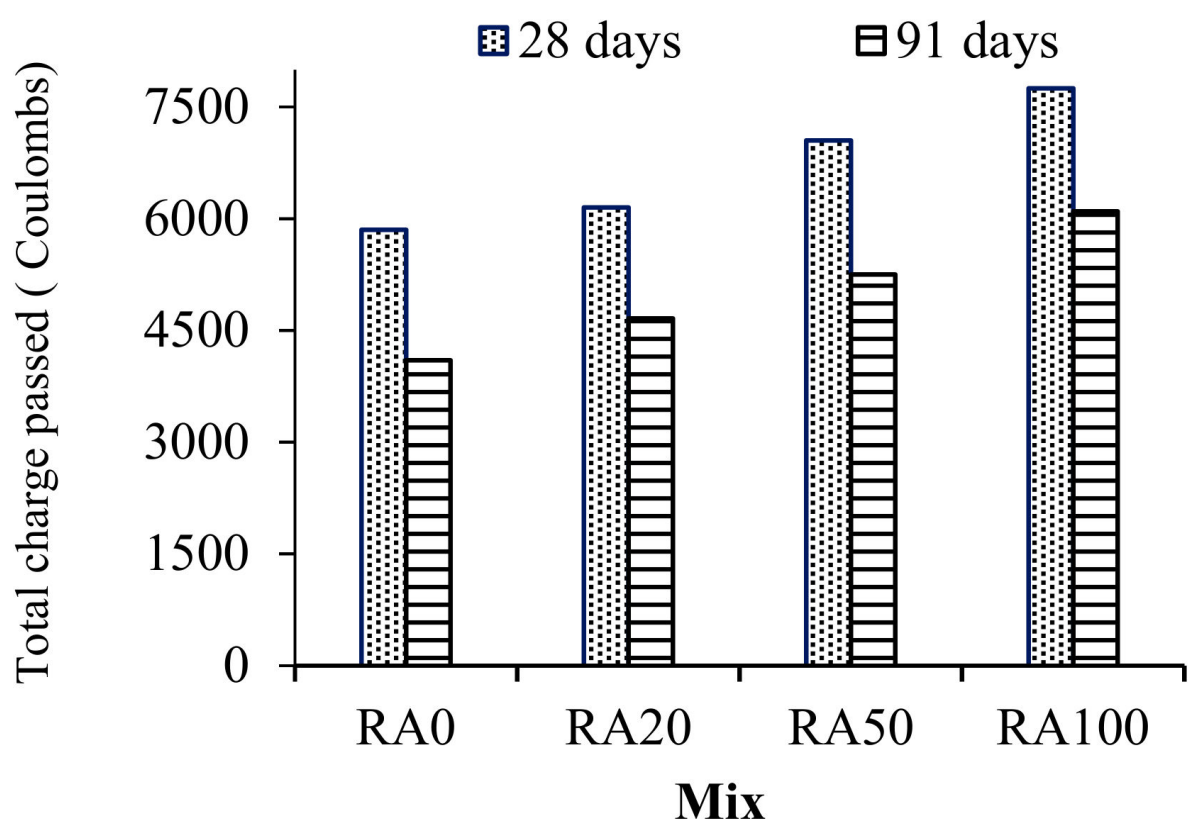

Figure 12. Chloride-ion penetration at 28 days and 90 days [151]. Reprinted with permission from Silva et al. [151]. 


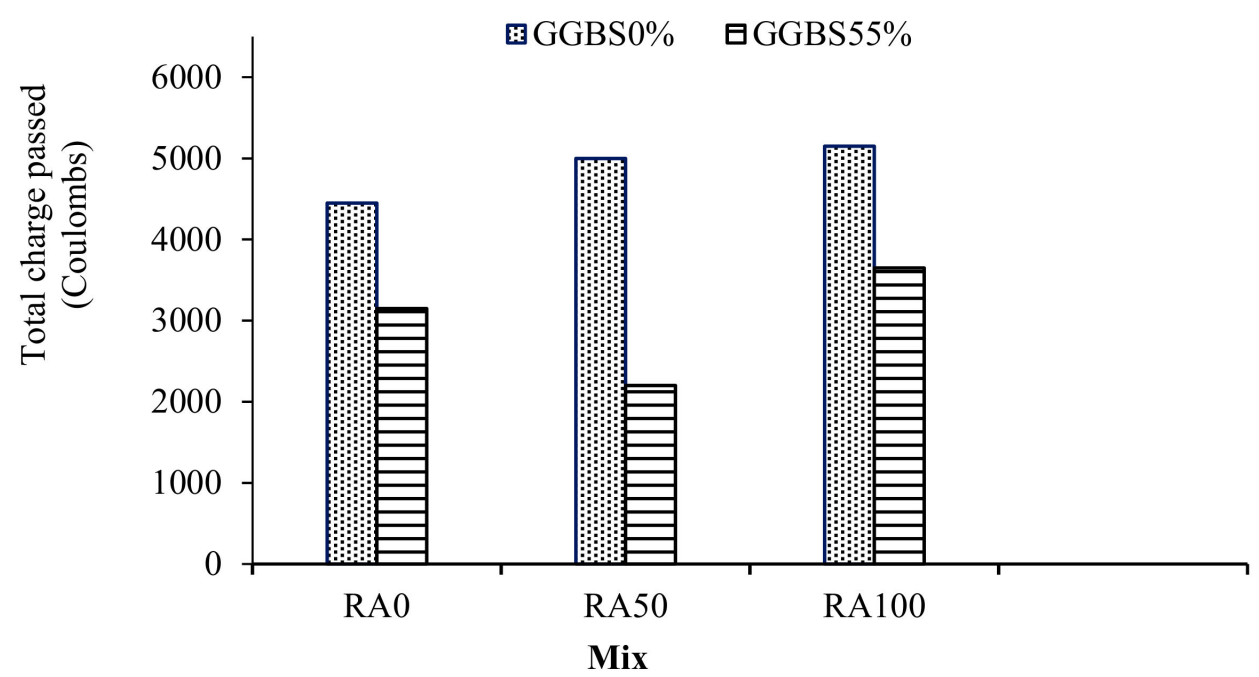

Figure 13. Chloride-ion penetration with 55\% of GGBS at 28 days [151]. Reprinted with permission from Silva et al. [151].

\subsection{Carbonation Resistance}

With regard to concrete carbonation, existing research points to conflicting effects of RCA. The researchers [102] reported that carbonation depth decreases with increasing RCA content, resulting in better performance except for $100 \%$ replacement. RCA concretes require a higher cement content to achieve identical strength to NCA concrete at the same water to cement ratio [102]. The higher the cement content, the higher the alkali reserves, which affect the depth of concrete carbonization. In contrast, it is found that at the same water-to-cement ratio, RCA concrete has a greater carbonization depth than NCA concretes [152,153]. In addition, the carbonization rate of RCA concrete is four times that of NCA concrete. Increased carbonation can increase the risk of reinforcing steel corrosion in RCA concretes. Increased concrete pavement, appropriate additional cementitious materials, corrects curing, and a lower water to cement ratio can counterbalance such risks. On the other hand, previous studies have reported that concrete containing the RA requires to more supplementary materials with high fineness to act as pore fillers. Thus, this will reduce the diffusion of carbon dioxide and slow down the speed of carbonation $[154,155]$ (See Figures 14 and 15). However, more research is needed to analyze the effect of RCA on concrete carbonation resistance.

\subsection{Resistance to Alkalis and Acid}

Resistance of RCA concrete to alkali-silica reactions depends on the RCA sources $[12,139,156]$. It is noted that RCA obtained from old concretes containing alkalis affects the resistance of newly created RCA concretes to alkali-silica reactions [12]. The results of the researcher showed that the amount of new concretes made using RCA increased disproportionately due to alkaline-silica reactions. The use of low-lime grade F fly ash can significantly minimize expansion due to alkaline silica reactions in RCA concretes. Ziyi Peng and others suggested a method in their study to improve RCA quality by absorbing silica fume slurry into residual mortar for RCA [157] (See Figures 16 and 17).

There is insufficient information available to draw specific conclusions about the alkali-silica reactivity of RCA concrete. Several studies recommend the use of SCMs to dilute AAR in recycled and RCI concrete [157].

It is noted that the acid resistance of RCA concrete is similar or slightly lower than that of NCA concrete [86]. Scientists immersed concrete samples in test baths containing sulfuric acid at $\mathrm{pH}=2$ to test the acid degradation rate of RCA concrete. Compared to NCA concrete, the penetration of acids into RCA concrete was slightly higher. This may be due to the correlation of acid penetration with high of the porosity and absorption of the RAC and residual mortar compared to that of natural aggregates in concrete [158]. This 
caused a higher penetration of the acid ions into the concrete, thus caused the dissolution of calcium hydroxide and the destruction of the gel calcification ( $\mathrm{CSH}$ ) in the concrete 8 However, researchers have shown that the acid attack resistance of RCA concrete can be improved by adding cement supplementary materials. Kazmi et al. demonstrate the possibility of treating RAC by immersion in the lime with accelerated carbonization and immersion in acetic acid with friction techniques [92] (See Figure 18). This method can be used to improve the acid resistance of RAC-containing concrete in chemically aggressive environments. More studies of RCA concrete under acidic conditions are needed to test their durability due to the small amount of research.

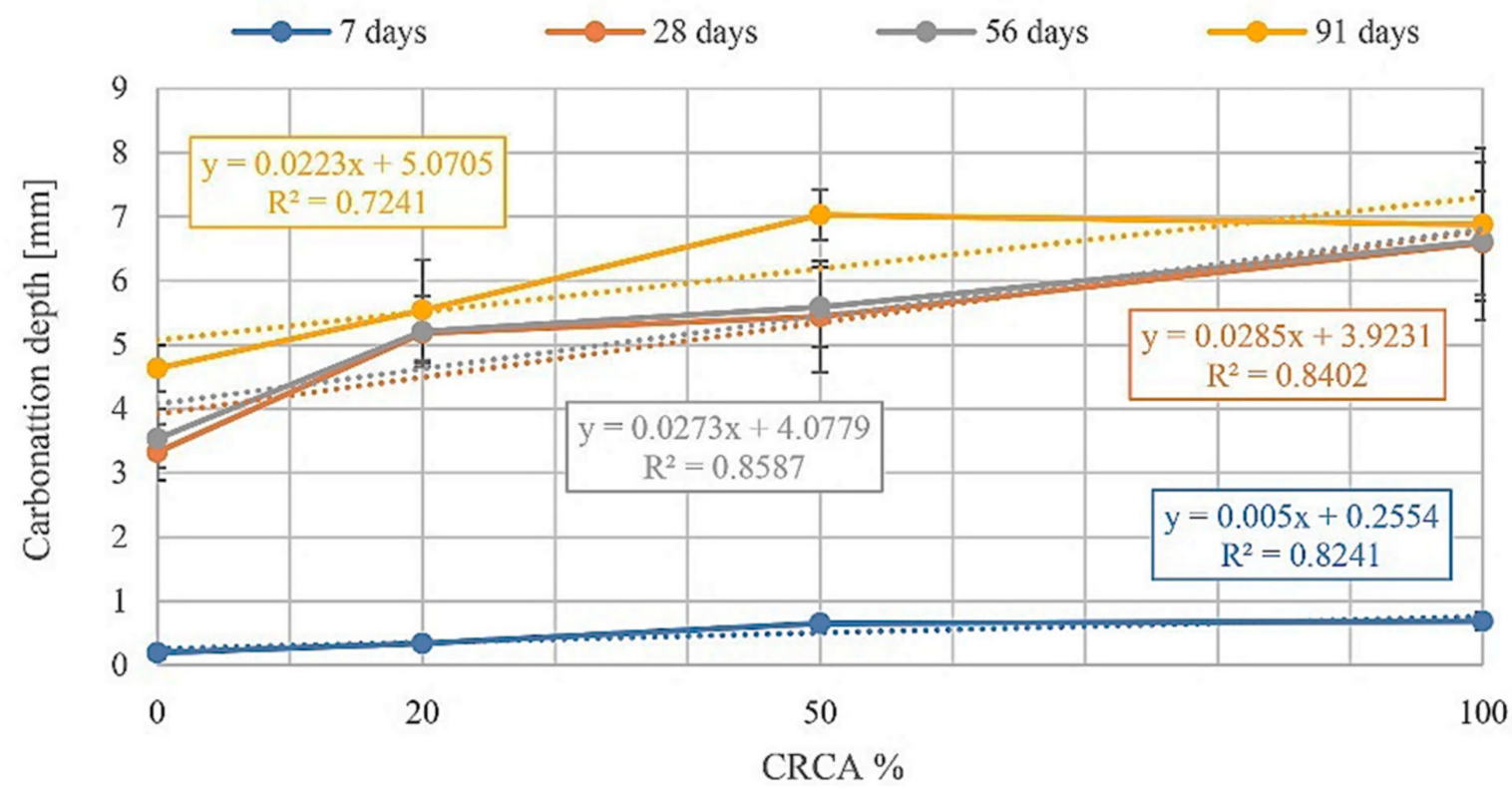

Figure 14. Relation between carbonation depth and coarse recycled concrete aggregates (\%) [155]. Reprinted with permission from Elsevier [155].

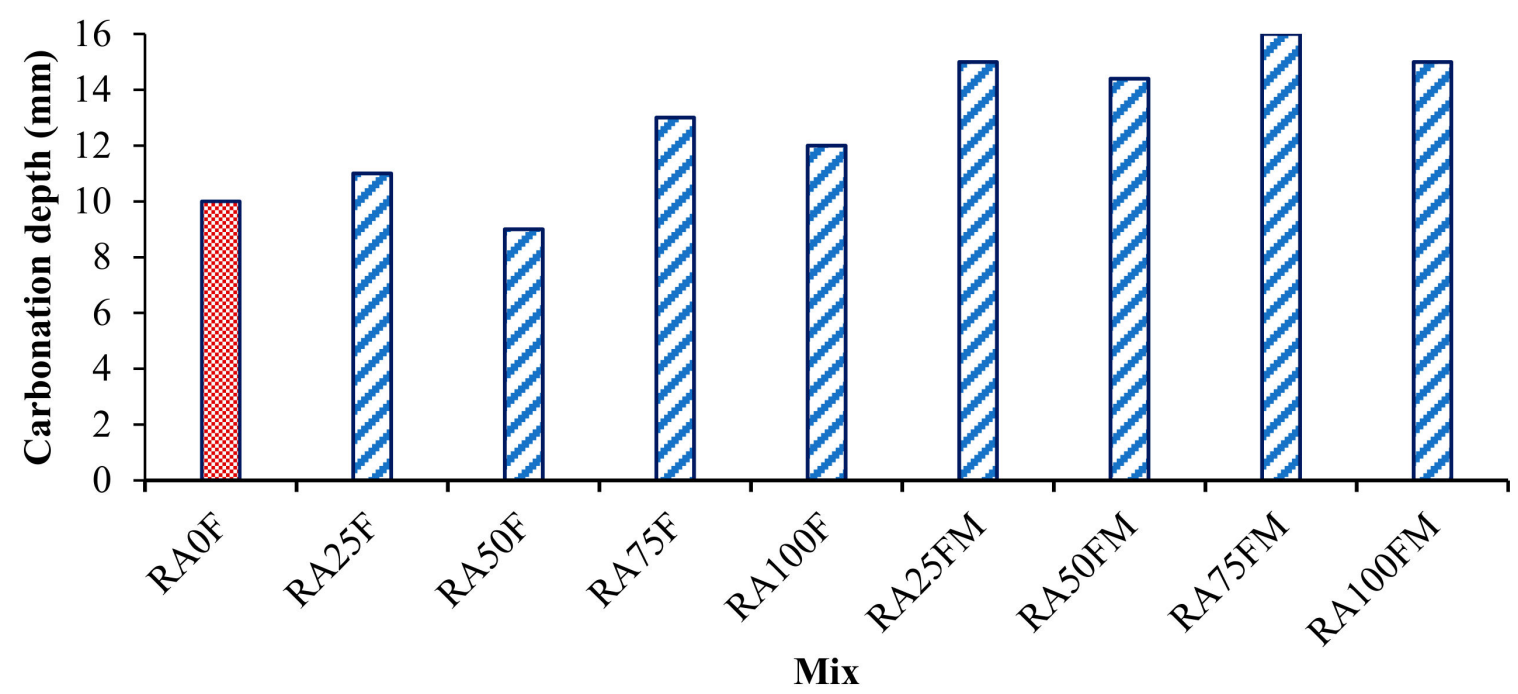

Figure 15. Effect of addition of RCA, FA and MK on concrete carbonation depths an exposure period of 4 weeks [154]. RA0F: without RCA with 30\% of FA, RA25F: $25 \%$ of RCA with $30 \%$ of FA. RA50F: $50 \%$ of RCA with $30 \%$ FA, RA100F: $100 \%$ of RCA with $30 \%$ FA, RA25FM: $25 \%$ of RCA with $30 \%$ of FA \& $10 \%$ of MK, RA50FM: $50 \%$ of RCA with $30 \%$ of FA \& $10 \%$ of MK, RA100FM:100\% of RCA with 30\% of FA \& 10\% of MK. Reprinted with permission from Elsevier [154]. 


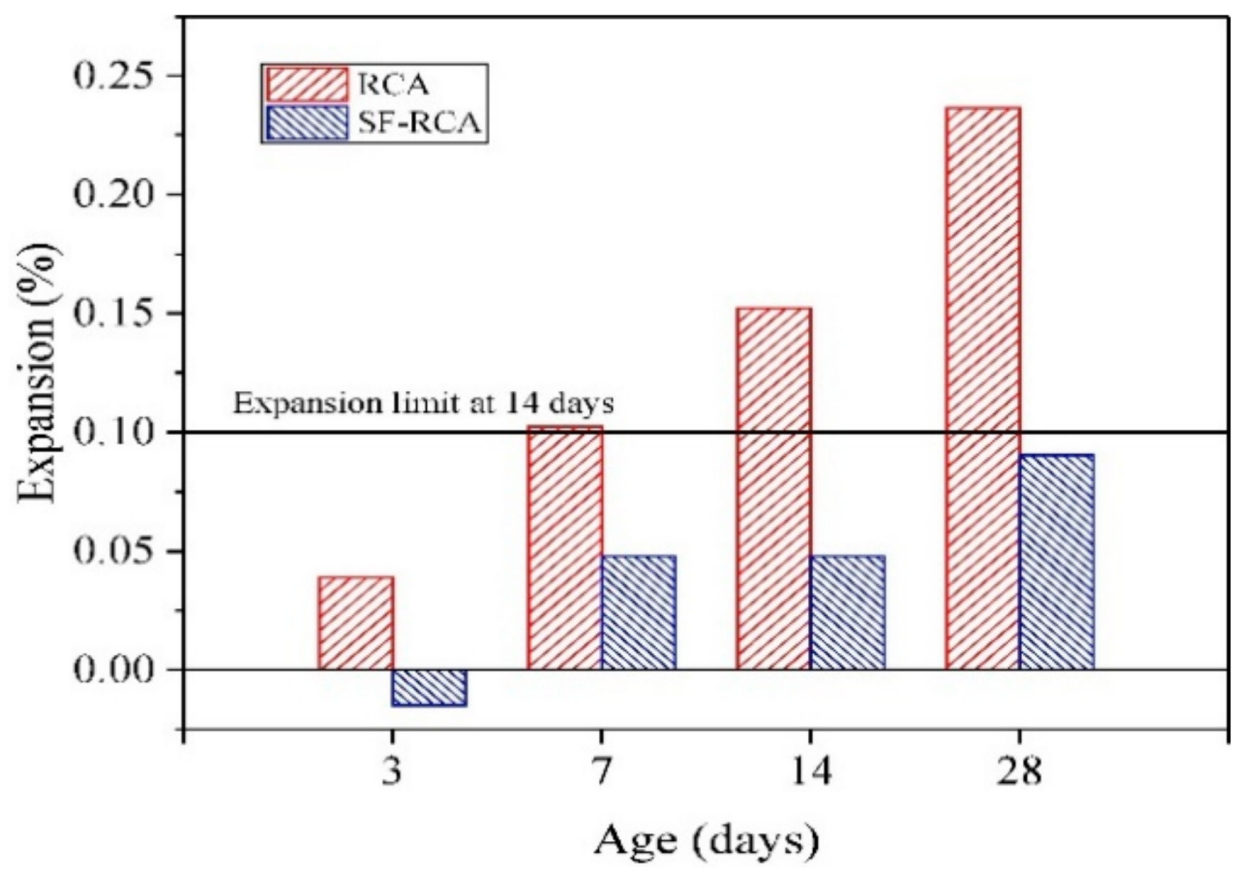

Figure 16. Mitigation of AAR expansion of RCA by sucking fine pozzolanic material into residual mortar [157]. Reprinted with permission from Elsevier [157].

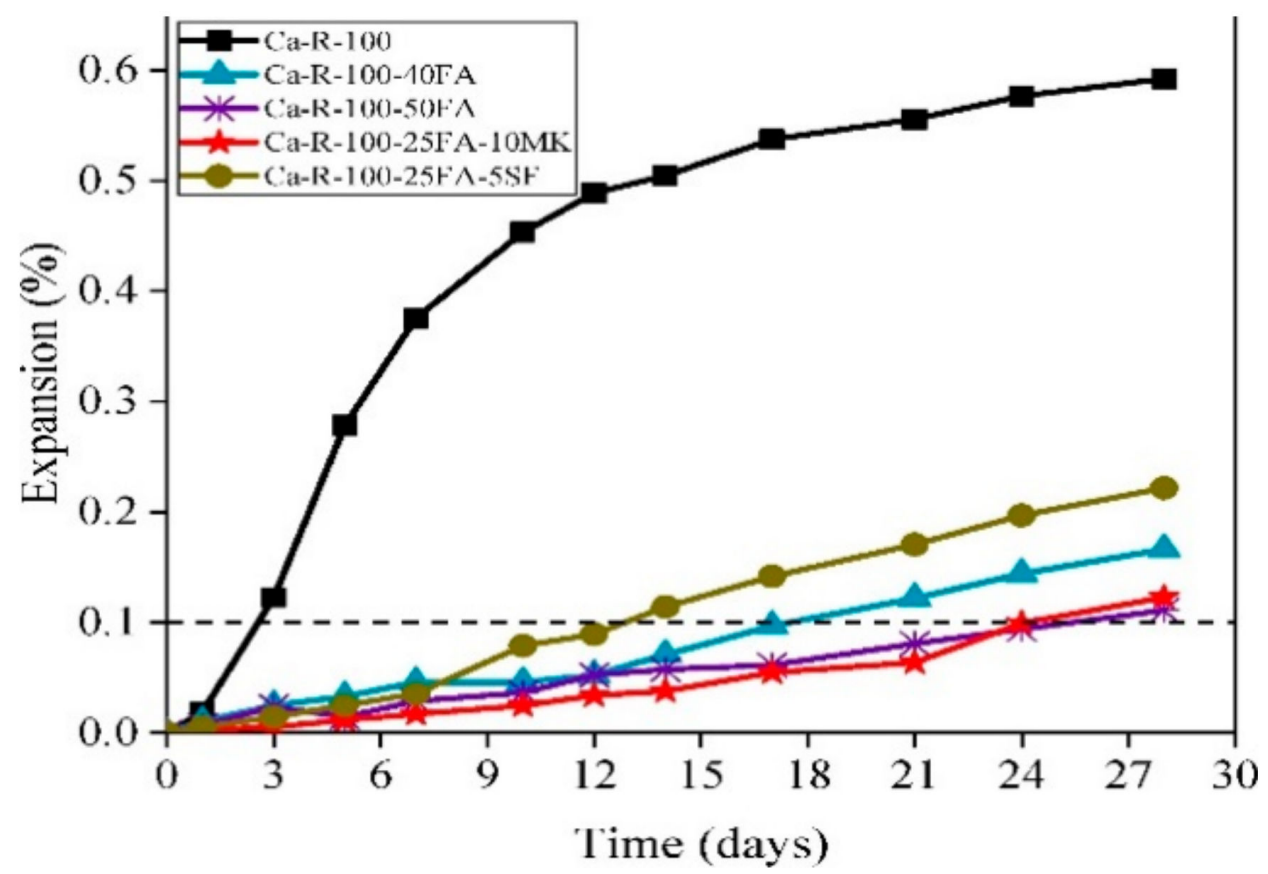

Figure 17. Expansions of RCA with various cementitious material blends [157]. Reprinted with permission from Elsevier [157].

\subsection{Freeze-Thaw Resistance}

Various researchers have noted that RCA concrete has sufficient resistance to freezethaw cycles $[141,159,160]$. There is evidence that repeated recycling of RCA concrete further improves frost resistance [161]. For RCA concretes, some researchers have reported similar or slightly reduced frost resistance compared to NCA concretes 10 In addition, concretes made from dry and water-saturated RCA have a lower resistance to freeze-thaw. RCA Concretes prepared using water-saturated concretes have shown better results due to 
improved anchoring at joints between pastes and aggregates. Previous studies showed that the effect of freeze-thaw was greater in mixtures with higher $\mathrm{w} / \mathrm{b}$ ratio and higher $\mathrm{RCA}$ content. However, the effect of $\mathrm{w} / \mathrm{b}$ ratio on freeze-thaw through percentage of weight change is more significant. The increase in the $\mathrm{w} / \mathrm{b}$ ratio increased the number and size of the capillary pores as well as the freeze water in the cement paste, causing mainly the extended internal pressure during freezing. In addition, a strong relationship was observed between freeze-thaw damage and water absorption of mixtures $[159,162]$ (See Figures 19-21). However, more research is needed to confirm the effect of RCA on concrete resistance to freezing and thawing.

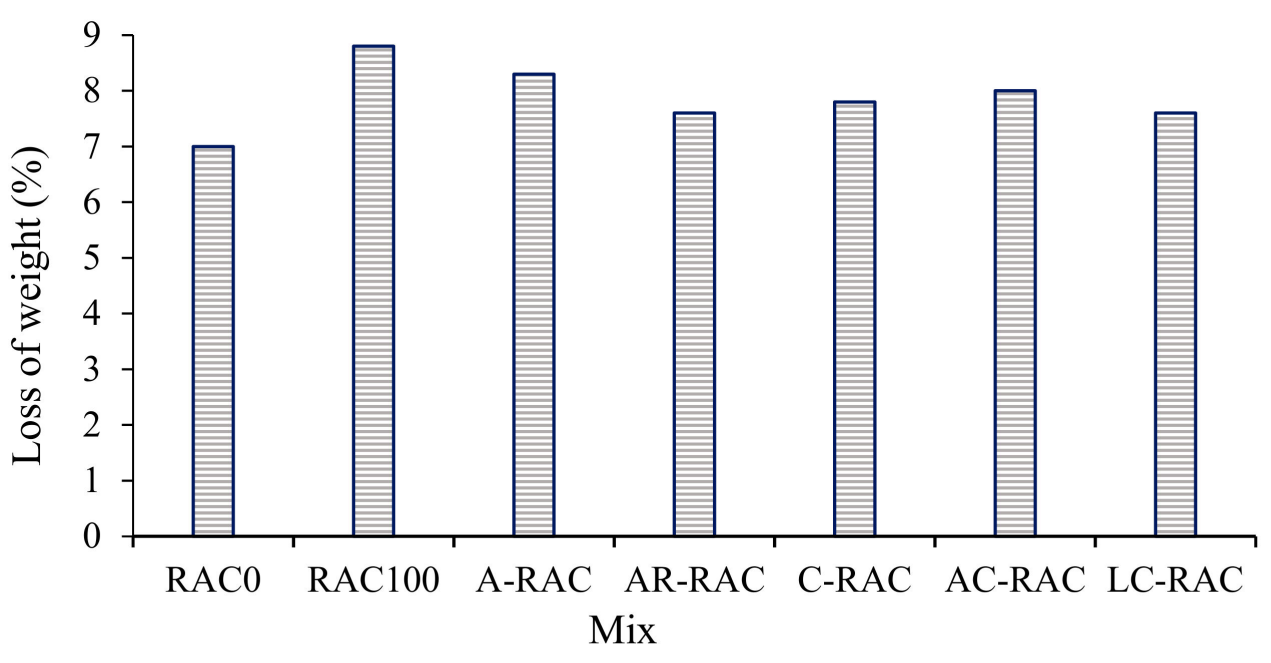

\begin{tabular}{cccccccc}
\multirow{2}{*}{ Porosity of CA $(\%)$} & NA & RA & A-RA & AR-RA & C-RA & AC-RA & LC-RA \\
\cline { 2 - 8 } & 3.19 & 19.46 & 15.94 & 15.31 & 14.39 & 15.79 & 11.65 \\
\hline
\end{tabular}

Figure 18. Loss in weight of NAC and RAC having untreated and treated RA after acid immersion [92]. Reprinted with permission from Elsevier [92].

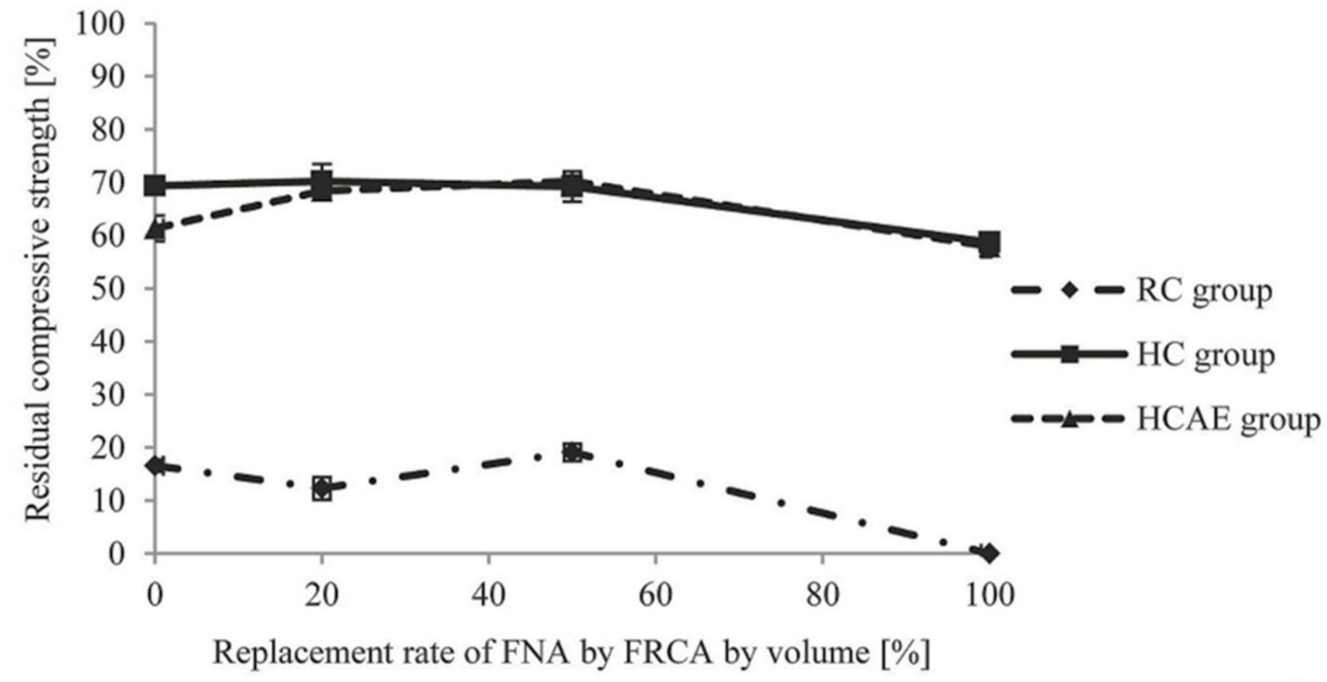

Figure 19. Residual compressive strengths of the mixes after 300 freeze-thaw cycles [159]. FNA: Fine aggregate, RC: Normal strength concrete, HC: High-strength concrete and HCAE: HC with air entraining agent. Reprinted with permission from Elsevier [159]. 


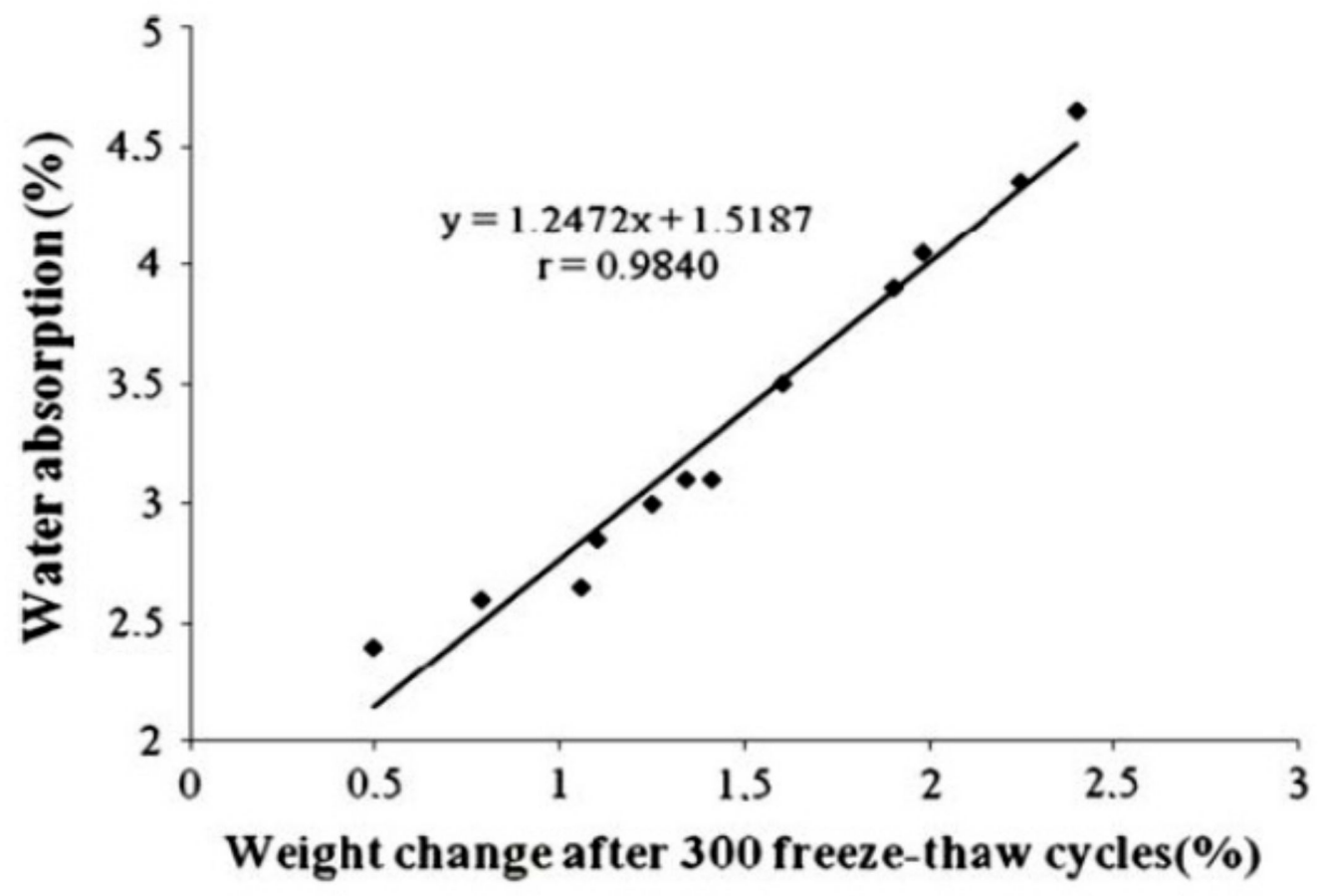

Figure 20. Relationship between water absorption and weight change percentages of after 300 freezethaw cycles [162]. Reprinted with permission from Elsevier [162].

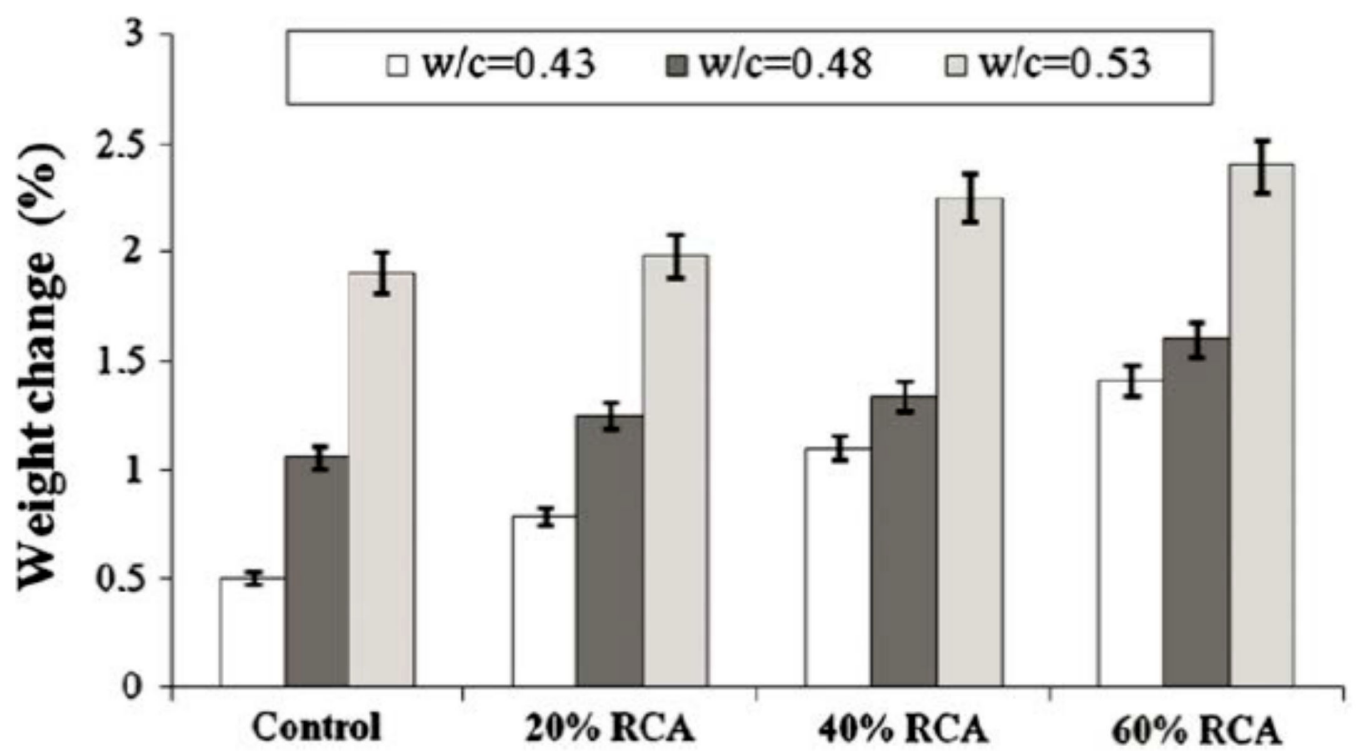

Figure 21. Weight change percentage after 300 freeze-thaw cycles [162]. Reprinted with permission from Elsevier [162].

\section{Improvement Methods for RCA Concretes}

\subsection{RCA Quality Improvements and Adjusting the Ratio of Water and Cement}

It is tested heat treatment methods to improve RCA quality [71]. It was noted that RCAs are rationally comparable to the traditional used aggregate removed from the river after heat treatment at $800{ }^{\circ} \mathrm{C}$. It is found that the strength of concrete was adversely affected by unwashed RCA used in concrete mixes [79]. However, the reduction in strength was offset by the use of rinsed RCAs. It is reported that the correct adjustment of the water balance of cement mixes for concrete mixes can increase the strength of RCA concrete [6]. It is have proposed a higher cement content in RCA concrete and a lower water to cement 
ratio than NCA concrete to achieve similar compressive strength [11]. It is similarly noted that lowering the water-to-cement ratio to certain levels was very beneficial for RCA concretes to establish an equivalent thaw and freeze resistance to those NCA concretes [43].

\subsection{Pozzolanic Materials Integration and Soaking of RCA in Pozzolanic Liquids}

The strength and durability of RCA concrete can be increased through the use of appropriate pozzolanic substances $[87,98,99]$. It is showed that the use of $65 \%$ fine granular blast furnace slag and 30\% pulverized fly ash improved the RCA compressive strength of concrete to control levels of concrete pouring with clean granite gravel [98]. In addition, fine-grained blast-furnace slags and pulverized fuel ash have been successful in increasing the resistance to chloride ion penetration into RCA concrete. Also, silica fumes have been found to significantly improve chloride permeation resistance for RCA concrete. The RCA concrete strengths may be boosted by either allowing reclaimed aggregates to soak up parts of mixing water without or with pozzolanic liquids during mixings or soaking the RCAs in mixes of pozzolanic liquids such as colloidal silicas or water before mixing of concretes. The micro-cracks in RCAs are expected to be filled up by the absorbed pozzolanic liquids or absorbed water with cement gels during pozzolanic reactions or cement hydrations. Therefore, the RCA concrete strengths can be increased.

\subsection{Uses of New Mixing and Curing Techniques}

It is used two-phase mixing approaches to obtain better quality RCA concrete (Table 5). These scientists used reclaimed aggregates treated with pozzolanic powders to improve the properties of RCA concrete [99]. In addition, the authors [87] have developed a two-phase mixing technique to ensure high-quality use of RCA concretes. These researchers found that, compared to NCA concrete, $100 \%$ replacement of virgin concrete aggregate is possible through their mixing approaches to create RCA concrete with suitable characteristics, although the optimal scenario is with $20 \%$ NCA replacement. The results of the determination of strength and slump showed that the new mixing methods significantly contributed to the achievement of high values of flexural and compressive strengths, as well as better workability. In addition, using scanning electron microscopes, interfacial transition zones between RCA concrete surfaces were realized. The scanning electron microscopes results established that the new mixing techniques promoted dense microstructures. Internal leaks in additives can be minimized by mixing techniques. The use of long-term cure in a humid environment is another approach to improving the performance of RCA concrete $[54,100,102]$. One of the most widely used approaches to reducing the carbonization rate of RCA concrete is the long-term cure. In RCA concretes, the carbonization depth is almost half when the concrete is cured with water. It is also reported that the common assumption that RCA is more sensitive to different curing conditions and therefore removes another obstacle to its massive use. [163]. Furthermore, Table 6 shows the ratio of RCA replacement criteria for making structural grades [34].

\subsection{Microstructure of RAC}

Recycled aggregate used to produce concrete differs from natural aggregate in that it contains old mortar attached to the surface of the aggregate. The RCA recycling process often requires crushing of the concrete parts, so the microstructure of the RCA is exposed to many defects such as micro-cracks, porosity, as well as weakening of the ITZ. Damage to the aggregate microstructure will damage the engineering properties and durability of the concrete containing the recycled aggregate.

In fact, all types of aggregate produced of broken concrete are a composite material consisting of natural aggregate and cement mortar (See Figures 22-26). These broken parts use to completely or partially replace natural aggregates after crushing to small particles [164]. The RCA consists of NA and an old cement mortar, so the RAC consists of three ITZ regions, as follows [164]. First, between NA and old cement matrix, Second, between NA and the new cement matrix, third, between new and old cement matrix. 
Several studies focus on studying the transition zone and its relationship to concrete degradation and weakness. The degradation of concrete often depends on the entity of a filtering path across the interface (See Figures 22-26). The transition region, i.e., the interface between the particle assembly and the bulk cement matrix [165]. To reduce this problem, suggestions are made regarding the durability adopted in National Concrete Standards [165-167] that include limits on the minimum cement content as well as on the maximum water-to-cement ratio used for structural concrete. Further, it is also reported that the incorporation of pozzolanic materials, such as silica fume, fly ash and slag, with different mixing methods and accelerated carbonation can improve the microstructure of RCA [168].

Table 6. Ratio of RCA replacement criteria for making structural grades [34].

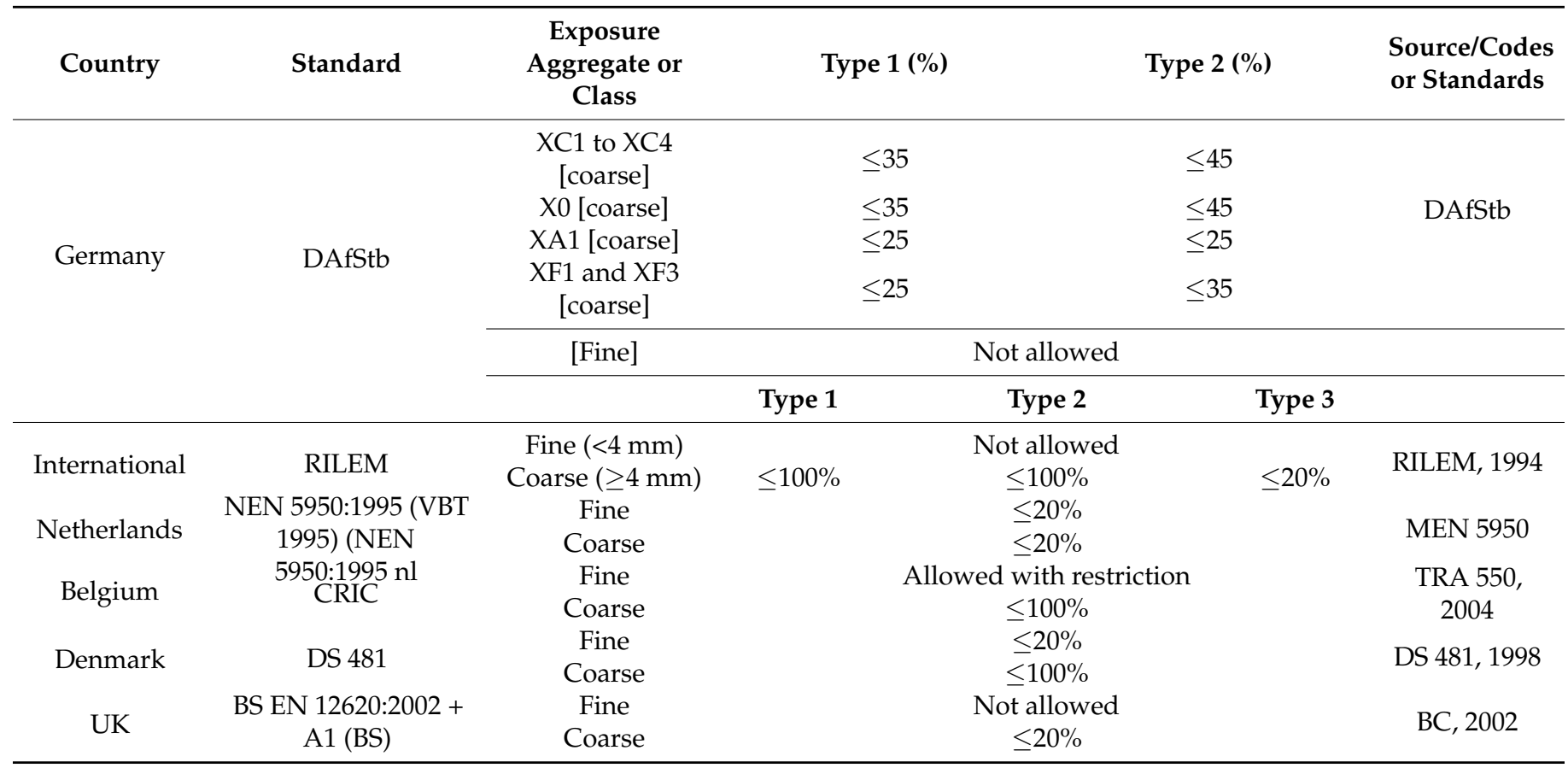
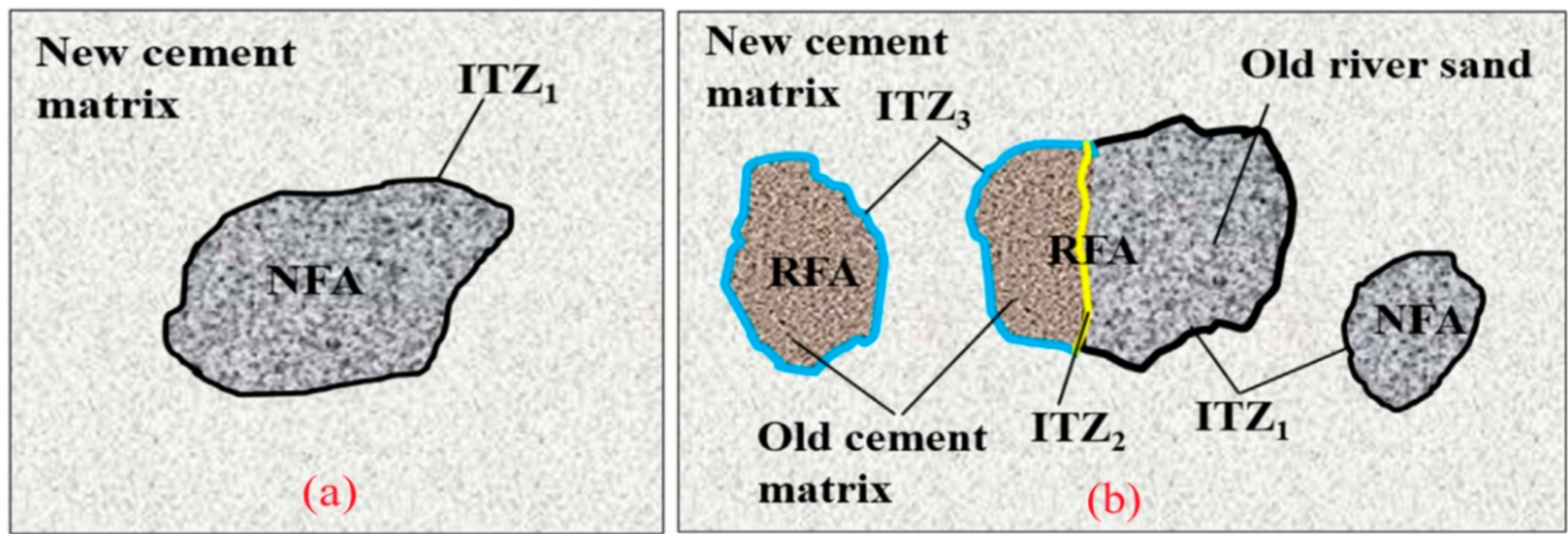

Figure 22. The different types of ITZs contained in concrete prepared with different fine aggregate: (a) NFA (quartz or river sand), and (b) in concrete with NFA partially replaced by RFA [167]. Reprinted with permission from Elsevier [167]. 


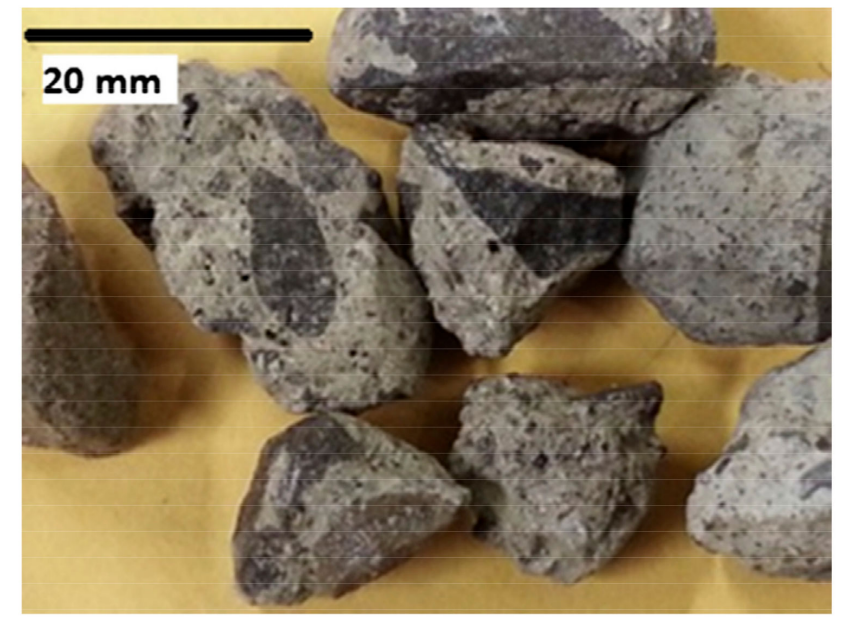

Figure 23. A low magnification image showing adhered cement in a RAC [87]. Reprinted with permission from Elsevier [87].

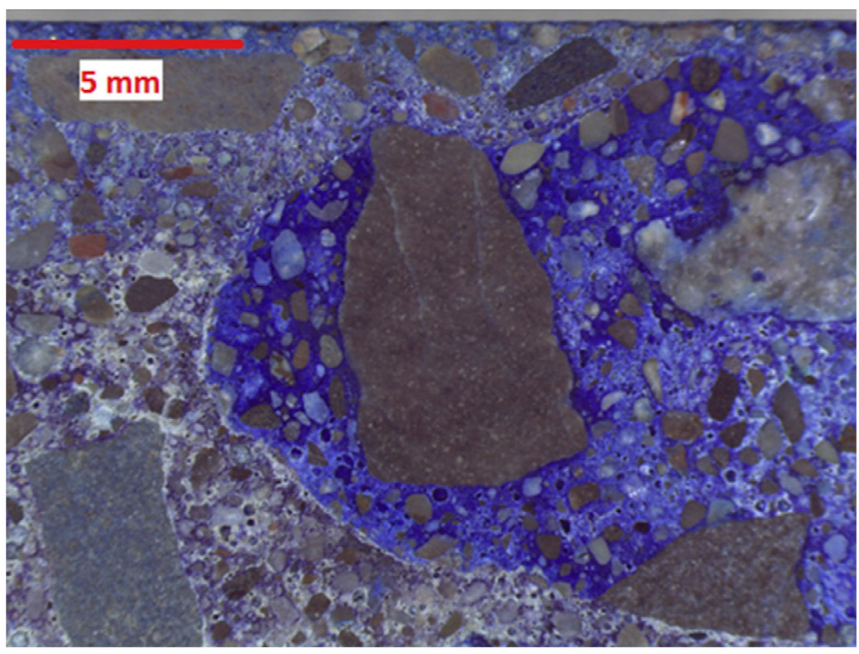

Figure 24. SEM images for polished section in concrete with RCA [87]. Reprinted with permission from Elsevier [87].

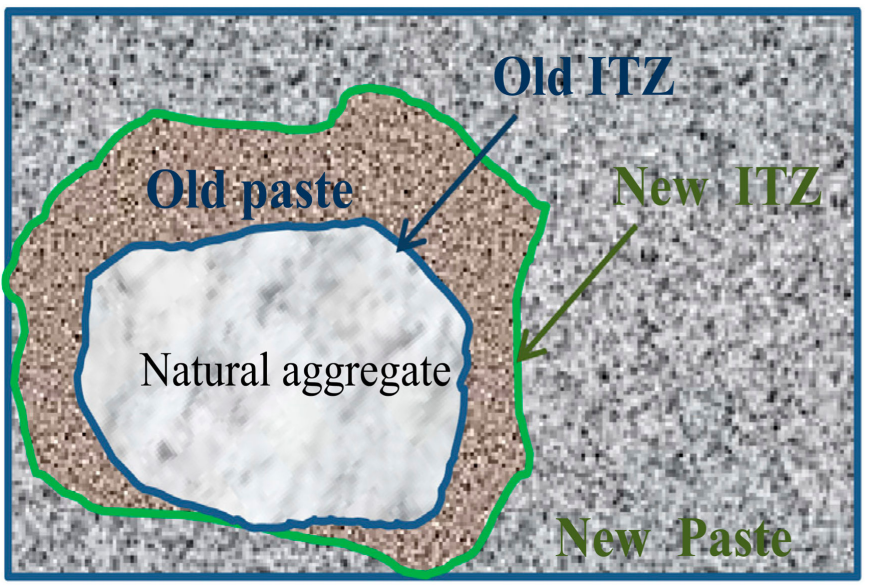

Figure 25. Sectional view of RCA in concrete including the old and new ITZ [169]. Reprinted with permission from [169]. 


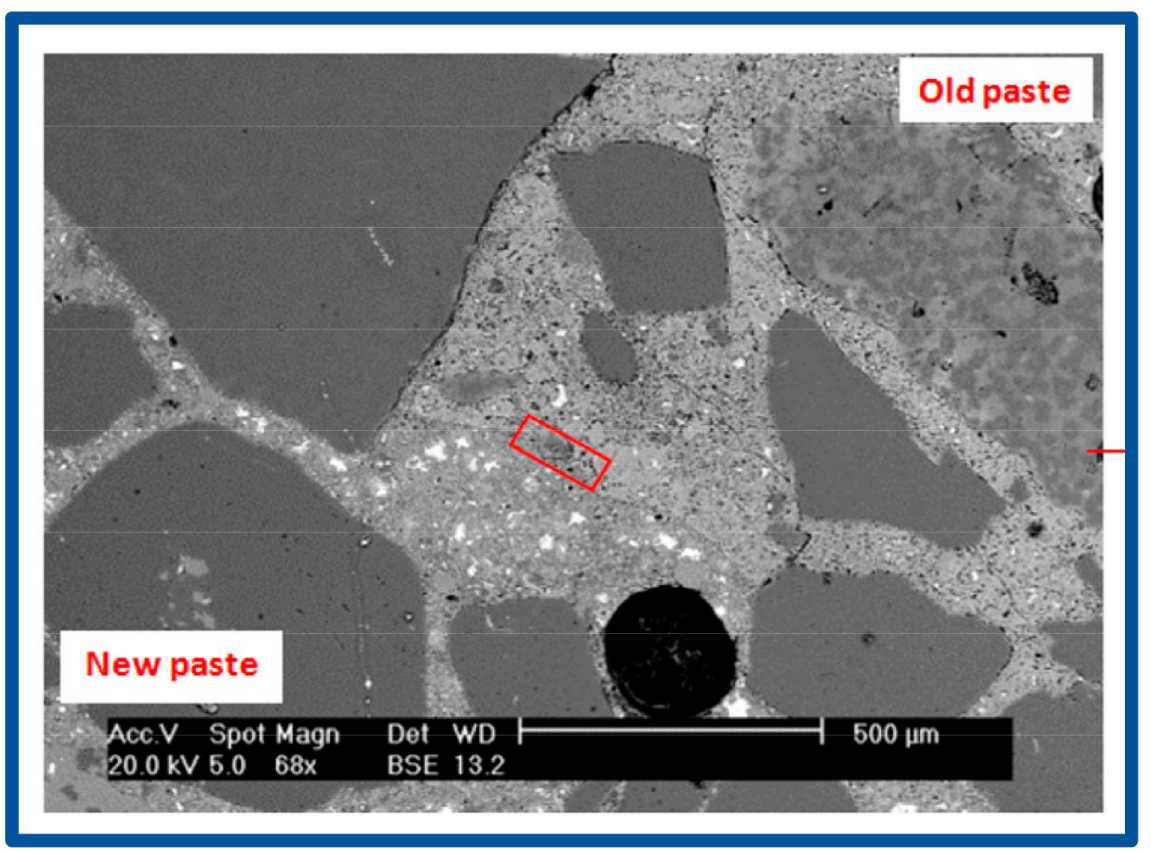

Figure 26. SEM images of interfacial transition zones in RAC [169]. Reprinted with permission from Elsevier [169].

On the other hand, the micro-pores in the mortar attached to the old rubble can contribute to retaining additional quantities of water, which may help to provide a selftreatment that leads to the promotion of filling the pores with moisturizing products (gel) [170]. Thus RA behaves as an internal curing agent, which also improves the ITZ between particles of aggregate and cement paste afterwards reduces the size of the pores within the microstructure of the concrete [171,172] (See Figure 27). This improvement is caused by a better inter-bond between the cement paste and the aggregate particles providing cross-linking sites for the cement paste resulting in better cement wetting and denser ITZ more uniform. The fracture value of aggregate, size, and porosity of ITZ has paradoxical effects on concrete's transport properties.


Figure 27. The ITZ between RCA and New Mortar Mixes; (a) 100\% natural aggregates and (b) 75\% natural aggregates + $25 \%$ recycled aggregates [171]. Reprinted with permission from Sadek and El-Attar [171]. 


\subsection{Treatment of $R C A$}

Due to the varying performance of RCA and its negative impact on most of the properties and concrete durability, several studies have suggested methods for treating RCAs in order to improve their properties and promote its application in the concrete industry safely [172]. The treatment methods depend on several factors, including the source, type of aggregate, and applications of RCA-containing concrete. The studies have suggested different approaches.

- Accelerated carbonization This method has been suggested by researchers [173,174]. This method is based on obtaining carbonated recycled aggregates. For this purpose, first, the RCA was stored at $25{ }^{\circ} \mathrm{C}$ and $\mathrm{RH}$ of $50 \%$ for $72 \mathrm{~h}$ days in order to provide the RA with a basic RH between $40 \%-70 \%$ that accommodates the accelerated carbonation [174]. After that, the RCA was placed in a sealed chamber under pressure of -1.0 bar. After the pressure was stabilized, carbon dioxide was applied at a concentration of $100 \%$ with a pressure of +0.8 bar for $24 \mathrm{~h}$ [175].

- Immersion in saturated lime water In order to improve the RCA performance through accelerated carbonization, the reactive components in the old adhesive slurries of RA play a vital role [174]. So, this method recommends submerging the RCA in lime-saturated water for $24 \mathrm{~h}$, and then placing it in a room at $25^{\circ} \mathrm{C}$ and $50 \%$ relative humidity for $72 \mathrm{~h}$. This step aims to introduce some calcium into the pores of the old mortar attached to the RCA. After this step was completed, the carbonization process for the RCA treated by immersion in saturated lime water was carried out. The same accelerated carbonization technique described above was used in order to obtain recycled aggregates carbonized with lime [175].

- Treatment with acetic acid This method uses acetic acid to remove the old mortar attached to the RCA. First, the RCAs are washed to remove the dirt and then directly immersed in a 3\% acetic acid solution for $24 \mathrm{~h}$. Next, the RCAs are washed again and dried to obtain recycled aggregates treated with acetic acid. After that, mechanical rubbing was performed for 5 minutes using an empty concrete mixer, based on the previous study $[175,176]$.

- Silica fume impregnation In this method, a solution of raw silica fume was prepared $1 \mathrm{~kg}$ per 10 liters of water, and a superplasticizer ( $1 \%$ of the mass of silica fume) was added to help disperse the silica fume particles and ensure their distribution on the surface of the RAC [176]. Then, it was placed in a $24 \mathrm{~h}$ drying oven, followed by cooling to room temperature and soaking in a silica fume solution for $24 \mathrm{~h}$. In the final stage, the saturated RAC was dried again in the oven to ensure proper penetration of silica fume particles into the surface of the RAC [53].

- Ultrasonic cleaning The crushed concrete was cleaned in an ultrasound bath to remove residual slurry on the surface of the untreated aggregate. The RAC was immersed in an ultrasound bath and treated for 10 minutes, after which the water was replaced with clean water, and the debris was cleaned for an additional 10 minutes. These operations are repeated several times until a clean RAC was obtained [53].

- Pre-soaking treatment methods This method is based on soaking the RCA in an acidic environment at about $20^{\circ} \mathrm{C}$ for $24 \mathrm{~h}$, followed by washing the RCA with distilled water to remove the acidic solvents. After that, the RCA was soaked in water for $24 \mathrm{~h}$ to ensure the disposal of acids or sticky mortar residues. In this method, three acidic solvents with a concentration of $0.1 \mathrm{~mol}$ can be used, which is an acidic environment suitable for removing the old mortar attached to the RCA, as it will not reduce the quality of the RCA. The acids applied in this method are phosphoric acid $\left(\mathrm{H}_{3} \mathrm{PO}_{4}\right)$, sulfuric acid $\left(\mathrm{H}_{2} \mathrm{SO}_{4}\right)$, or hydrochloric acid $(\mathrm{HCl})[177]$.

\section{Practical, Economical, and Environmental Issues of RCA Concretes}

Obviously, for the economic feasibility of RCA production, ready-mix concrete plants can be used to obtain production scale for production. Economic impact assessment is effective when it is considered that the action of the case does not require additional 
payment. He looks at the recycling of waste concrete in ready-mixed concrete plants as infrastructure and construction resources. The prototype developed is based on information obtained from various industrial shops as well as concrete processing shops, which are used as a scenario study to estimate the additional commercial price of a product. The current problems facing Thailand, where there are so many landfills for concrete waste as a result of destruction plans, and inappropriate concrete is being disposed of, will be addressed using RCA production [72]. The growth in RCA replacement is primarily associated with an increase in additional unit costs of resources. In particular, the replacement of the cement content is increased as a result of the increase in the RCA replacement ratio. The increase in RCA cost is associated with additional quality control and pre-processing costs. However, upfront costs can be reduced by going directly to a high quality concrete plant.

Compared to a recycling approach where construction waste is used in recycling plants to obtain new materials, the traditional costs are very high [178]. The first stage of the recycling process includes construction waste that is disposed of at low cost recycling facilities. Additional costs include energy consumption and transportation costs. The second stage is stockpiling, in which lone workers are employed at a rate of $\$ 18$ an hour. The third step is sorting with machines, such as a shredder and excavator. Also accrued are additional costs for equipment maintenance, labor, fuel, fixed indirect costs, working capital, operating costs, equipment costs, and capital costs [75]. Crushing processes in the fourth phase include magnetic separation, primary crushing, and secondary crushing. This includes fuel costs, fixed indirect costs, operating costs, working capital, and capital costs. With magnetic separation, the process also includes sorting steel scrap and sells for about $\$ 100$ per ton. The casting phase includes manual removal processes in which pieces of paper, wood, and plastic are separated from the grounded concrete. In this process, the wages are about $\$ 18$ an hour. The sixth stage involves sitting in the air, watching, and doing laundry, which is identical to the traditional approach. Recycled fuel and water are used to deposit dust particles at this stage [178]. The final stages of the refining process include finished products that sell for between $\$ 14$ and $\$ 22$ per ton.

Thus, compared to the traditional approach, RCA has the most cost-effective gain [75]. The financial benefits of recycling concrete lead to longer-term benefits than using natural concrete. Sensitivity analysis is performed, taking into account the main parameter due to the expected uncertainties with the main variables used in the model [153]. The purpose of the analysis is to determine the main variable impact of modification on one unit of output. The main factors to be taken into account are transport distance, additional costs for RCA pretreatment, additional cement required to produce RCA, and RCA composition [138]. Due to depleted natural resources, crushed concrete for demolition is produced in large quantities and must be used in an environmentally friendly and economical manner. Deterministic values are defined as means because the parameters have normal distribution characteristics. The range of input variables can be estimated to determine upper and lower bounds. The RCA price cap range is determined by breaking down changes in the value of a product by changes in quantities [148].

\section{Comments and Further Researches}

The literature in this paper is summarized to provide comprehensive insights into the potential applications of RCA to produce green and sustainable concrete composites that contribute to environmentally friendly buildings. Therefore, differences in the current state of knowledge between RCAs and NCAs are highlighted, and some suggestions for future research are provided. In addition, this study also contributed to uncovering deficiencies in previous research and studies, which requires further research and investigation into the following points:

1. Estimating the cost of recycled aggregates based on supply and demand, as well as, to many different challenges that must be considered.

2. Utilizing recycled aggregates to obtain a regime of self-curing (internal curing) for concrete, especially for aggregates that have a high pore ratio. 
3. The role of chemical components of cement paste adhering on aggregates in the stability and soundness of concrete.

4. Study the role of methods for treating recycled aggregates in order to improve the transport properties of concrete.

5. More understanding of the relationship between microstructures and properties of concrete containing RCA.

\section{Conclusions}

Reclaimed destroyed concrete has a significant potential for value-added applications to maximize environmental and economic benefits. Significant savings can be achieved by making RCA a valuable resource in the new generation of concrete. In the current study, a critical analysis of a recycled concrete aggregate for the production of heavy-duty concrete structures was carried out. The following conclusions were drawn from this article:

1. As a substitute for natural aggregate, RCA are useful for the production of concretes of standard strength and properties. The main problem with using RCA in new concretes, however, is their incompatible qualities, especially when they come from the demolition of old concrete buildings.

2. By complying with standard virgin aggregate specifications, RCA can be effectively used in new concrete. However, RCA requires new guidelines and specifications.

3. The physical characteristics of RCA strongly influence the properties of hardened and fresh concrete. The magnitude of crushing, aggregate abrasion, and impact viscosity affect the strength characteristics of the concrete. In addition, the negative chemical characteristics of RCA can affect the durability of RCA concrete and, therefore, their performance in service.

4. Total $100 \%$ RCA can produce standard quality concrete. Concretes produced with RCA generally have about $81 \%$ of that of NCA concrete. Insufficiently dense transition zones between bulk cement pastes and RCA and unfavorable RCA properties cause a decrease in the strength of RCA concrete.

5. The use of crushed RCA in new concrete mixes requires careful research, since the reclaimed fines further reduce the strength of the concrete. Replacement of natural sand with RCAs is usually up to $20 \%$.

6. The performance of RCA concrete can be improved by long-term curing, new mixing methods, the addition of pozzolanic substances, and changing the ratio of water to cement.

7. In high quality concretes such as self-compacting, high strength, and high performance concretes, RCA can be used with proper mix design and material selection.

8. Concretes having RCA can be properly designed and balanced to reduce the effect of RCA on its hardened and fresh strength and characteristics, regardless of the differences in performance between natural concrete aggregates and re-concrete aggregates. The chemical impurities of RCA must be reduced to advance its use in the concrete sector.

The following are the summaries of recommendations:

1. The idea of using existing production facilities to produce recycled concrete aggregate is misplaced as the construction manager may initiate excessive additional costs as a result of the specific conditions of the halls. Nanotechnology can be used to advance RCA manufacturing because of its enormous potential to improve production and quality in high-efficiency apprenticeship manufacturing. In addition, the use of nanotechnology is aimed at changing the operating mode in construction using nanomaterials. The examination describes several properties of RCA at the nanoscale using a variety of state of the art equipment. Therefore, it is worth focusing on nanosciences, which is critical when investigating the microstructure of RCA. In addition, the strength characteristics of RCA can be improved through the use of nanomaterials to obtain greater strength than conventional concretes. 
2. Incorporating high performance pozzolans into recycled concrete aggregate to improve RCA performance is likely to increase its cost of use. However, an assessment of the cost-benefit of increasing the amount of fly ash shows that this is necessary due to the increase in strength. Poor quality concrete is one of the problems associated with using recycled resources.

3. In order to accelerate the implementation of the production of secondary concrete aggregate, its use should be included in government projects. The integration of advanced manufacturing technologies that improve quality is essential to reduce the cost of using recycled concrete aggregate. These technologies can be used through client funding and government, including incentives that can support this process. To support this idea, all workers must complete homeschooling programs to facilitate a process that is likely to improve attention to the environment.

Author Contributions: Conceptualization, N.M., R.F. and M.A.; methodology, N.M., R.F., M.A. and A.M.Z.; validation, N.M., R.F., M.A., A.M.Z., G.M., N.V., S.K., T.O. and Y.V.; resources, N.M., R.F., M.A., A.M.Z., G.M., N.V., S.K., T.O. and Y.V.; data curation, N.M., R.F., M.A., A.M.Z., G.M., N.V., S.K., T.O. and Y.V.; writing-original draft preparation, N.M., R.F., M.A. and A.M.Z.; writing-review and editing, N.M., R.F., M.A., A.M.Z., G.M., N.V., S.K., T.O. and Y.V.; supervision, M.A. and R.F.; project administration, R.F., M.A. and N.V.; funding acquisition, M.A., N.V., S.K. and Y.V. All authors have read and agreed to the published version of the manuscript.

Funding: No fund available.

Institutional Review Board Statement: Not applicable.

Informed Consent Statement: Not applicable.

Data Availability Statement: Data sharing not applicable.

Acknowledgments: The authors gratefully acknowledge the support given by Deanship of Scientific Research at Prince Sattam bin Abdulaziz University, Alkharj, Saudi Arabia; Moscow Automobile and Road Construction University, Moscow, Russia; and the Department of Civil Engineering, Faculty of Engineering and IT, Amran University, Yemen, for this research.

Conflicts of Interest: The authors declare no conflict of interest.

\section{References}

1. Fediuk, R.; Pak, A.; Kuzmin, D. Fine-Grained Concrete of Composite Binder. IOP Conf. Ser. Mater. Sci. Eng. 2017, 262, 012025. [CrossRef]

2. Lesovik, V.S.; Glagolev, E.S.; Popov, D.Y.; Lesovik, G.A.; Ageeva, M.S. Textile-reinforced concrete using composite binder based on new types of mineral raw materials. IOP Conf. Ser. Mater. Sci. Eng. 2018, 327, 032033. [CrossRef]

3. Klyuev, S.V.; Klyuev, A.V.; Khezhev, T.A.; Pukharenko, Y.V. High-strength fine-grained fiber concrete with combined reinforcement by fiber. J. Eng. Appl. Sci. 2018, 13, 6407-6412. [CrossRef]

4. $\quad$ Fediuk, R.S.; Lesovik, V.S.; Svintsov, A.P.; Mochalov, A.V.; Kulichkov, S.V.; Stoyushko, N.Y.; Gladkova, N.A.; Timokhin, R.A. Self-compacting concrete using pretreatmented rice husk ash. Mag. Civ. Eng. 2018, 79, 66-76. [CrossRef]

5. de Brito, J.; Agrela, F.; Silva, R.V. Construction and demolition waste. In New Trends in Eco-Efficient and Recycled Concrete; Woodhead Publishing: Cambridge, UK, 2018. [CrossRef]

6. Abdel-Hay, A.S. Properties of recycled concrete aggregate under different curing conditions. HBRC J. 2017, 13, 271-276. [CrossRef]

7. Pavlu, T.; Kocí, V.; Hájek, P. Environmental assessment of two use cycles of recycled aggregate concrete. Sustainability 2019, 11, 6185. [CrossRef]

8. Abdulmatin, A.; Tangchirapat, W.; Jaturapitakkul, C. Environmentally friendly interlocking concrete paving block containing new cementing material and recycled concrete aggregate. Eur. J. Environ. Civ. Eng. 2019, 23, 1467-1484. [CrossRef]

9. Rizvi, R.; Tighe, S.L.; Henderson, V.; Norris, J. Incorporating recycled concrete aggregate in pervious concrete pavements. In Proceedings of the 2009 Annual Conference and Exhibition of the Transportation Association of Canada-Transportation in a Climate of Change, Vancouver, BC, Canada, 18-21 October 2009.

10. Shin, M.; Kim, K.; Gwon, S.W.; Cha, S. Durability of sustainable sulfur concrete with fly ash and recycled aggregate against chemical and weathering environments. Constr. Build. Mater. 2014, 69, 167-176. [CrossRef]

11. Abdel-Shafy, H.I.; Mansour, M.S.M. Solid waste issue: Sources, composition, disposal, recycling, and valorization. Egypt. J. Pet. 2018, 27, 1275-1290. [CrossRef] 
12. Kenai, S. Recycled aggregates. In Waste and Supplementary Cementitious Materials in Concrete; Woodhead Publishing: Cambridge, UK, 2018. [CrossRef]

13. Marinković, S.; Radonjanin, V.; Malešev, M.; Ignjatović, I. Comparative environmental assessment of natural and recycled aggregate concrete. Waste Manag. 2010, 30, 2255-2264. [CrossRef]

14. Pacheco-Torgal, F.; Tam, V.W.Y.; Labrincha, J.A.; Ding, Y.; de Brito, J. Handbook of Recycled Concrete and Demolition Waste; Woodhead Publishing: Cambridge, UK, 2013. [CrossRef]

15. Al-Bayati, H.K.A.; Tighe, S.L.; Achebe, J. Influence of recycled concrete aggregate on volumetric properties of hot mix asphalt. Resour. Conserv. Recycl. 2018, 130, 200-214. [CrossRef]

16. Lee, C.H.; Du, J.C.; Shen, D.H. Evaluation of pre-coated recycled concrete aggregate for hot mix asphalt. Constr. Build. Mater. 2012, 28, 66-71. [CrossRef]

17. Cho, Y.H.; Yun, T.; Kim, I.T.; Choi, N.R. The application of Recycled Concrete Aggregate (RCA) for Hot Mix Asphalt (HMA) base layer aggregate. KSCE J. Civ. Eng. 2011, 15, 473-478. [CrossRef]

18. Zulkati, A.; Wong, Y.D.; Sun, D.D. Mechanistic performance of asphalt-concrete mixture incorporating coarse recycled concrete aggregate. J. Mater. Civ. Eng. 2013, 25, 1299-1305. [CrossRef]

19. Carpenter, S.H.; Wolosick, J.R. Modifier Influence in the Characterization of Hot-Mix Recycled Material. Transp. Res. Rec. J. Transp. Res. Board. 1980, 777, 15-22.

20. Gálvez-Martos, J.L.; Styles, D.; Schoenberger, H.; Zeschmar-Lahl, B. Construction and demolition waste best management practice in Europe. Resour. Conserv. Recycl. 2018, 136, 166-178. [CrossRef]

21. Yuan, H.; Shen, L. Trend of the research on construction and demolition waste management. Waste Manag. 2011, 31, 670-679. [CrossRef] [PubMed]

22. Yeheyis, M.; Hewage, K.; Alam, M.S.; Eskicioglu, C.; Sadiq, R. An overview of construction and demolition waste management in Canada: A lifecycle analysis approach to sustainability. Clean Technol. Environ. Policy 2013, 15, 81-91. [CrossRef]

23. Mália, M.; de Brito, J.; Pinheiro, M.D.; Bravo, M. Construction and demolition waste indicators. Waste Manag. Res. 2013, 31, 241-255. [CrossRef]

24. Wu, Z.; Yu, A.T.W.; Shen, L.; Liu, G. Quantifying construction and demolition waste: An analytical review. Waste Manag. 2014, 34, 1683-1692. [CrossRef]

25. Akhtar, A.; Sarmah, A.K. Construction and demolition waste generation and properties of recycled aggregate concrete: A global perspective. J. Clean. Prod. 2018, 186, 262-281. [CrossRef]

26. Blengini, G.A. Life cycle of buildings, demolition and recycling potential: A case study in Turin, Italy. Build. Environ. 2009, 44, 319-330. [CrossRef]

27. Butera, S.; Christensen, T.H.; Astrup, T.F. Life cycle assessment of construction and demolition waste management. Waste Manag. 2015, 44, 196-205. [CrossRef] [PubMed]

28. Poon, C.S. Management of construction and demolition waste. Waste Manag. 2007, 27, 159-160. [CrossRef]

29. S Lockrey, H.N.; Crossin, K.V. Recycling the construction and demolition waste in Vietnam: Opportunities and challenges in practice. J. Clean. Prod. 2016, 133, 757-766. [CrossRef]

30. Al-Swaidani, A.M.; Khwies, W.T. Applicability of Artificial Neural Networks to Predict Mechanical and Permeability Properties of Volcanic Scoria-Based Concrete. Adv. Civ. Eng. 2018, 2018, 5207962. [CrossRef]

31. Dahlbo, H.; Bachér, J.; Lähtinen, K.; Jouttijärvi, T.; Suoheimo, P.; Mattila, T.; Sironen, S.; Myllymaa, T.; Saramäki, K. Construction and demolition waste management-A holistic evaluation of environmental performance. J. Clean. Prod. 2015, 107, 333-341. [CrossRef]

32. Coelho, A.; de Brito, J. Influence of construction and demolition waste management on the environmental impact of buildings. Waste Manag. 2012, 32, 532-541. [CrossRef]

33. AS 1141.6.2. Methods for Sampling and Testing Aggregates Method 6.2: Particle Density and Water Absorption of Coarse AggregatePycnometer Method; Standards Australia: Sydney, Australia, 1996.

34. McNeil, K.; Kang, T.H.K. Recycled Concrete Aggregates: A Review. Int. J. Concr. Struct. Mater. 2013, 7, 61-69. [CrossRef]

35. JIS-5022. Recycled Concrete Using Recycled Aggregate Class M; Japanese Standards Association: Tokyo, Japan, 2012.

36. Kim, K.H.; Ahn, J.W.; Lee, D.J.; Cho, H.C. Development of recycled aggregate producing process from waste concrete using autogenous mill and density separation. In Proceedings of the REWAS 2008: Global Symposium on Recycling, Waste Treatment and Clean Technology, Cancun, Mexico, 12-15 October 2008.

37. De Schutter, G.; Ye, G.; Audenaert, K.; Bager, D.; Baroghel-Bouny, V.; Bellmann, F.; Boel, V.; Bonen, D.; Boström, L.; Corradi, M.; et al. Final report of RILEM TC 205-DSC: Durability of self-compacting concrete. Mater. Struct. Constr. 2008, 41, $225-233$. [CrossRef]

38. EHE-08. Code on Structural Concrete; Ministerio de Transportes, Movilidad y Agenda Urbana: Madrid, Spanish, 2010.

39. Shi, C.; Li, Y.; Zhang, J.; Li, W.; Chong, L.; Xie, Z. Performance enhancement of recycled concrete aggregate-A review. J. Clean. Prod. 2016, 112, 466-472. [CrossRef]

40. Li, W.; Xiao, J.; Sun, Z.; Kawashima, S.; Shah, S.P. Interfacial transition zones in recycled aggregate concrete with different mixing approaches. Constr. Build. Mater. 2012, 35, 1045-1055. [CrossRef]

41. Poon, C.S.; Shui, Z.H.; Lam, L. Effect of microstructure of ITZ on compressive strength of concrete prepared with recycled aggregates. Constr. Build. Mater. 2004, 18, 461-468. [CrossRef] 
42. Etxeberria, M.; Vázquez, E.; Marí, A.; Barra, M. Influence of amount of recycled coarse aggregates and production process on properties of recycled aggregate concrete. Cem. Concr. Res. 2007, 11, 10094-10101. [CrossRef]

43. Almeida, A.; Cunha, J. The implementation of an Activity-Based Costing (ABC) system in a manufacturing company. Procedia Manuf. 2017, 13, 932-939. [CrossRef]

44. Malešev, M.; Radonjanin, V.; Marinković, S. Recycled concrete as aggregate for structural concrete production. Sustainability 2010, 2, 1204-1225. [CrossRef]

45. Tabsh, S.W.; Abdelfatah, A.S. Influence of recycled concrete aggregates on strength properties of concrete. Constr. Build. Mater. 2009, 81, 179-186. [CrossRef]

46. Guo, H.; Shi, C.; Guan, X.; Zhu, J.; Ding, Y.; Ling, T.C.; Zhang, H.; Wang, Y. Durability of recycled aggregate concrete-A review. Cem. Concr. Compos. 2018, 89, 251-259. [CrossRef]

47. Tam, V.W.Y.; Gao, X.F.; Tam, C.M. Microstructural analysis of recycled aggregate concrete produced from two-stage mixing approach. Cem. Concr. Res. 2005, 35, 1195-1203. [CrossRef]

48. Otsuki, N.; Miyazato, S.I.; Yodsudjai, W. Influence of recycled aggregate on interfacial transition zone, strength, chloride penetration and carbonation of concrete. J. Mater. Civ. Eng. 2003, 15, 443-451. [CrossRef]

49. Silva, R.V.; Neves, R.; de Brito, J.; Dhir, R.K. Carbonation behaviour of recycled aggregate concrete. Cem. Concr. Compos. 2015, 62, 22-32. [CrossRef]

50. Radonjanin, V.; Malešev, M.; Marinković, S.; al Malty, A.E.S. Green recycled aggregate concrete. Constr. Build. Mater. 2013, 47, 1503-1511. [CrossRef]

51. Domingo-Cabo, A.; Lázaro, C.; López-Gayarre, F.; Serrano-López, M.A.; Serna, P.; Castaño-Tabares, J.O. Creep and shrinkage of recycled aggregate concrete. Constr. Build. Mater. 2009, 23, 2545-2553. [CrossRef]

52. Gómez-Soberón, J.M.V. Porosity of recycled concrete with substitution of recycled concrete aggregate: An experimental study. Cem. Concr. Res. 2002, 32, 1301-1311. [CrossRef]

53. Katz, A. Treatments for the improvement of recycled aggregate. J. Mater. Civ. Eng. 2004, 16, 597-603. [CrossRef]

54. Bui, N.K.; Satomi, T.; Takahashi, H. Mechanical properties of concrete containing $100 \%$ treated coarse recycled concrete aggregate. Constr. Build. Mater. 2018, 163, 496-507. [CrossRef]

55. Chatterjee, A.; Sui, T. Alternative fuels-Effects on clinker process and properties. Cem. Concr. Res. 2019, 123, 105777. [CrossRef]

56. Etxeberria, M.; Marí, A.R.; Vázquez, E. Recycled aggregate concrete as structural material. Mater. Struct. Constr. 2007, 40, 529-541. [CrossRef]

57. Sagoe-Crentsil, K.K.; Brown, T.; Taylor, A.H. Performance of concrete made with commercially produced coarse recycled concrete aggregate. Cem. Concr. Res. 2001, 31, 707-712. [CrossRef]

58. Tam, V.W.Y.; Soomro, M.; Evangelista, A.C.J. A review of recycled aggregate in concrete applications (2000-2017). Constr. Build. Mater. 2018, 172, 272-292. [CrossRef]

59. Duan, Z.H.; Kou, S.C.; Poon, C.S. Prediction of compressive strength of recycled aggregate concrete using artificial neural networks. Constr. Build. Mater. 2013, 40, 1200-1206. [CrossRef]

60. Bui, N.K.; Satomi, T.; Takahashi, H. Improvement of mechanical properties of recycled aggregate concrete basing on a new combination method between recycled aggregate and natural aggregate. Constr. Build. Mater. 2017, 148, 376-385. [CrossRef]

61. Corinaldesi, V. Mechanical and elastic behaviour of concretes made of recycled-concrete coarse aggregates. Constr. Build. Mater. 2010, 24, 1616-1620. [CrossRef]

62. Al-Bayati, H.K.A.; Das, P.K.; Tighe, S.L.; Baaj, H. Evaluation of various treatment methods for enhancing the physical and morphological properties of coarse recycled concrete aggregate. Constr. Build. Mater. 2016, 112, 284-298. [CrossRef]

63. Al-Bayati, H.K.A.; Tighe, S.L. Effect of Recycled Concrete Aggregate on Rutting and Stiffness Characteristics of Asphalt Mixtures. J. Mater. Civ. Eng. 2019, 31, 04019219. [CrossRef]

64. Elistratkin, M.Y.; Lesovik, V.S.; Zagorodnjuk, L.H.; Pospelova, E.A.; Shatalova, S.V. New point of view on materials development. IOP Conf. Ser. Mater. Sci. Eng. 2018, 327, 3-032020. [CrossRef]

65. Feduik, R. Reducing permeability of fiber concrete using composite binders. Spec. Top. Rev. Porous Media. 2018, 9, 79-89. [CrossRef]

66. Klyuev, S.V.; Klyuev, A.V.; Shorstova, E.S. The micro silicon additive effects on the fine-grassed concrete properties for 3-D additive technologies. Mater. Sci. Forum. 2019, 974, 131-135. [CrossRef]

67. Limbachiya, M.C.; Leelawat, T.; Dhir, R.K. Use of recycled concrete aggregate in high-strength concrete. Mater. Struct. Constr. 2000, 33, 574-580. [CrossRef]

68. Poon, C.S.; Shui, Z.H.; Lam, L.; Fok, H.; Kou, S.C. Influence of moisture states of natural and recycled aggregates on the slump and compressive strength of concrete. Cem. Concr. Res. 2004, 34, 31-36. [CrossRef]

69. Poon, C.S.; Kou, S.C.; Lam, L. Use of recycled aggregates in molded concrete bricks and blocks. Constr. Build. Mater. 2002, 16, 281-289. [CrossRef]

70. Ratnayake, R.M.C.; Samarakoon, S.M.S. Structural integrity assessment and control of ageing onshore and offshore structures. In Modeling and Simulation Techniques in Structural Engineering; Samui, P., Chakraborty, S., Kim, D., Eds.; IGI Global: Pennsylvania, PA, USA, 2016. [CrossRef]

71. Thongkamsuk, P.; Sudasna, K.; Tondee, T. Waste generated in high-rise buildings construction: A current situation in Thailand. Energy Procedia 2017, 138, 411-416. [CrossRef] 
72. Xuan, D.; Zhan, B.; Poon, C.S. Durability of recycled aggregate concrete prepared with carbonated recycled concrete aggregates. Cem. Concr. Compos. 2017, 84, 214-221. [CrossRef]

73. Wang, H.; Sun, X.; Wang, J.; Monteiro, P.J.M. Permeability of concrete with recycled concrete aggregate and pozzolanic materials under stress. Materials 2016, 9, 252. [CrossRef] [PubMed]

74. Wijayasundara, M.; Mendis, P.; Crawford, R.H. Methodology for the integrated assessment on the use of recycled concrete aggregate replacing natural aggregate in structural concrete. J. Clean. Prod. 2017, 166, 321-334. [CrossRef]

75. Wijayasundara, M.; Mendis, P.; Crawford, R.H. Integrated assessment of the use of recycled concrete aggregate replacing natural aggregate in structural concrete. J. Clean. Prod. 2018. [CrossRef]

76. Ajdukiewicz, A.; Kliszczewicz, A. Influence of recycled aggregates on mechanical properties of HS/HPC. Cem. Concr. Compos. 2002, 174, 591-604. [CrossRef]

77. Evangelista, L.; de Brito, J. Mechanical behaviour of concrete made with fine recycled concrete aggregates. Cem. Concr. Compos. 2007, 29, 397-401. [CrossRef]

78. Tam, V.W.Y. Economic comparison of concrete recycling: A case study approach. Resour. Conserv. Recycl. 2008, 52, 821-828. [CrossRef]

79. Verian, K.P.; Ashraf, W.; Cao, Y. Properties of recycled concrete aggregate and their influence in new concrete production. Resour. Conserv. Recycl. 2018, 133, 30-49. [CrossRef]

80. Oikonomou, N.D. Recycled concrete aggregates. Cem. Concr. Compos. 2005, 27, 315-318. [CrossRef]

81. Teh, S.H.; Wiedmann, T.; Moore, S. Mixed-unit hybrid life cycle assessment applied to the recycling of construction materials. J. Econ. Struct. 2018, 7, 1-25. [CrossRef]

82. Kisku, N.; Joshi, H.; Ansari, M.; Panda, S.K.; Nayak, S.; Dutta, S.C. A critical review and assessment for usage of recycled aggregate as sustainable construction material. Constr. Build. Mater. 2017, 131, 721-740. [CrossRef]

83. Tošić, N.; Marinković, S.; Dašić, T.; Stanić, M. Multicriteria optimization of natural and recycled aggregate concrete for structural use. J. Clean. Prod. 2015, 87, 766-776. [CrossRef]

84. Mas, B.; Cladera, A.; del Olmo, T.; Pitarch, F. Influence of the amount of mixed recycled aggregates on the properties of concrete for non-structural use. Constr. Build. Mater. 2012, 27, 612-622. [CrossRef]

85. Lye, C.Q.; Dhir, R.K.; Ghataora, G.S.; Li, H. Creep strain of recycled aggregate concrete. Constr. Build. Mater. 2016, 102, 244-259. [CrossRef]

86. Poon, C.S.; Chan, D. Effects of contaminants on the properties of concrete paving blocks prepared with recycled concrete aggregates. Constr. Build. Mater. 2007, 21, 164-175. [CrossRef]

87. Andal, J.; Shehata, M.; Zacarias, P. Properties of concrete containing recycled concrete aggregate of preserved quality. Constr. Build. Mater. 2016, 125, 842-855. [CrossRef]

88. Poon, C.S.; Lam, C.S. The effect of aggregate-to-cement ratio and types of aggregates on the properties of pre-cast concrete blocks. Cem. Concr. Compos. 2008, 30, 283-289. [CrossRef]

89. Khatib, J.M. Properties of concrete incorporating fine recycled aggregate. Cem. Concr. Res. 2005, 35, 763-769. [CrossRef]

90. Kou, S.C.; Poon, C.S. Enhancing the durability properties of concrete prepared with coarse recycled aggregate. Constr. Build. Mater. 2012, 35, 69-76. [CrossRef]

91. Zaetang, Y.; Sata, V.; Wongsa, A.; Chindaprasirt, P. Properties of pervious concrete containing recycled concrete block aggregate and recycled concrete aggregate. Constr. Build. Mater. 2016, 111, 15-21. [CrossRef]

92. Kazmi, S.M.S.; Munir, M.J.; Wu, Y.F.; Patnaikuni, I.; Zhou, Y.; Xing, F. Effect of recycled aggregate treatment techniques on the durability of concrete: A comparative evaluation. Constr. Build. Mater. 2020, 264, 120284. [CrossRef]

93. Al-Bayati, H.K.A.; Tighe, S.L. Utilizing a different technique for improving micro and macro characteristics of coarse recycled concrete aggregate. In Proceedings of the TAC 2016: Efficient Transportation-Managing the Demand-2016 Conference and Exhibition of the Transportation Association of Canada, Toronto, ON, Canada, 25-28 September 2016.

94. Limbachiya, M.; Meddah, M.S.; Ouchagour, Y. Use of recycled concrete aggregate in fly-ash concrete. Constr. Build. Mater. 2012, 27, 439-449. [CrossRef]

95. Padmini, A.K.; Ramamurthy, K.; Mathews, M.S. Influence of parent concrete on the properties of recycled aggregate concrete. Constr. Build. Mater. 2009, 23, 829-836. [CrossRef]

96. Yang, J.; Du, Q.; Bao, Y. Concrete with recycled concrete aggregate and crushed clay bricks. Constr. Build. Mater. 2011, 25, 1935-1945. [CrossRef]

97. Rahal, K. Mechanical properties of concrete with recycled coarse aggregate. Build. Environ. 2007, 35, 763-769. [CrossRef]

98. Arredondo-Rea, S.P.; Corral-Higuera, R.; Gómez-Soberón, J.M.; Gámez-García, D.C.; Bernal-Camacho, J.M.; Rosas-Casarez, C.A.; Ungsson-Nieblas, M.J. Durability parameters of reinforced recycled aggregate concrete: Case study. Appl. Sci. $2019,9,617$. [CrossRef]

99. Aliabdo, A.A.; Elmoaty, A.E.M.A.; Fawzy, A.M. Experimental investigation on permeability indices and strength of modified pervious concrete with recycled concrete aggregate. Constr. Build. Mater. 2018, 193, 105-127. [CrossRef]

100. Dimitriou, G.; Savva, P.; Petrou, M.F. Enhancing mechanical and durability properties of recycled aggregate concrete. Constr. Build. Mater. 2018, 158, 228-235. [CrossRef]

101. Katz, A. Properties of concrete made with recycled aggregate from partially hydrated old concrete. Cem. Concr. Res. 2003, 33, 703-711. [CrossRef] 
102. Mohammed, S.I.; Najim, K.B. Mechanical strength, flexural behavior and fracture energy of Recycled Concrete Aggregate self-compacting concrete. Structures 2020, 23, 34-43. [CrossRef]

103. Martín-Morales, M.; Zamorano, M.; Ruiz-Moyano, A.; Valverde-Espinosa, I. Characterization of recycled aggregates construction and demolition waste for concrete production following the Spanish Structural Concrete Code EHE-08. Constr. Build. Mater. 2011, 25, 742-748. [CrossRef]

104. James, Use of Recycled Aggregate and Fly Ash in Concrete Pavement. Am. J. Eng. Appl. Sci. 2011, 4, 201-208. [CrossRef]

105. Ceia, F.; Raposo, J.; Guerra, M.; Júlio, E.; de Brito, J. Shear strength of recycled aggregate concrete to natural aggregate concrete interfaces. Constr. Build. Mater. 2016, 109, 139-145. [CrossRef]

106. Ajdukiewicz, A.B.; Kliszczewicz, A.T. Comparative Tests of Beams and Columns Made of Recycled Aggregate Concrete and Natural Aggregate Concrete. J. Adv. Concr. Technol. 2007, 5, 259-273. [CrossRef]

107. Lye, C.Q.; Dhir, R.K.; Ghataora, G.S. Shrinkage of recycled aggregate concrete. Proc. Inst. Civ. Eng. Struct. Build. 2016, 169, 867-891. [CrossRef]

108. Zega, C.J.; Villagrán-Zaccardi, Y.A.; di Maio, A.A. Effect of natural coarse aggregate type on the physical and mechanical properties of recycled coarse aggregates. Mater. Struct. Constr. 2010, 43, 195-202. [CrossRef]

109. Kleijer, A.L.; Lasvaux, S.; Citherlet, S.; Viviani, M. Product-specific Life Cycle Assessment of ready mix concrete: Comparison between a recycled and an ordinary concrete. Resour. Conserv. Recycl. 2017, 122, 210-218. [CrossRef]

110. Yazdanbakhsh, A.; Bank, L.C.; Chen, C. Use of recycled FRP reinforcing bar in concrete as coarse aggregate and its impact on the mechanical properties of concrete. Constr. Build. Mater. 2016, 121, 278-284. [CrossRef]

111. Mohseni, E.; Saadati, R.; Kordbacheh, N.; Parpinchi, Z.S.; Tang, W. Engineering and microstructural assessment of fibre-reinforced self-compacting concrete containing recycled coarse aggregate. J. Clean. Prod. 2017, 168, 605-613. [CrossRef]

112. Wijayasundara, M.; Mendis, P.; Crawford, R.H. Net incremental indirect external benefit of manufacturing recycled aggregate concrete. Waste Manag. 2018, 78, 279-291. [CrossRef]

113. Shaikh, F.U.A.; Nath, P.; Hosan, A.; John, M.; Biswas, W.K. Sustainability assessment of recycled aggregates concrete mixes containing industrial by-products. Mater. Today Sustain. 2019, 5, 100013. [CrossRef]

114. Hiete, M.; Stengel, J.; Ludwig, J.; Schultmann, F. Matching construction and demolition waste supply to recycling demand: A regional management chain model. Build. Res. Inf. 2011, 39, 333-351. [CrossRef]

115. Rodríguez, C.; Sánchez, I.; Miñano, I.; Benito, F.; Cabeza, M.; Parra, C. On the possibility of using recycled mixed aggregates and GICC thermal plant wastes in non-structural concrete elements. Sustainability 2019, 11, 633. [CrossRef]

116. Wagih, A.M.; El-Karmoty, H.Z.; Ebid, M.; Okba, S.H. Recycled construction and demolition concrete waste as aggregate for structural concrete. HBRC J. 2013, 9, 193-200. [CrossRef]

117. Sim, J.; Park, C. Compressive strength and resistance to chloride ion penetration and carbonation of recycled aggregate concrete with varying amount of fly ash and fine recycled aggregate. Waste Manag. 2011, 31, 2352-2360. [CrossRef] [PubMed]

118. Zega, C.J.; di Maio, Á.A. Use of recycled fine aggregate in concretes with durable requirements. Waste Manag. 2011, 31, 2336-2340. [CrossRef]

119. Eddine, B.T.; Salah, M.M. Solid waste as renewable source of energy: Current and future possibility in Algeria. Int. J. Energy Environ. Eng. 2012, 3, 1-12. [CrossRef]

120. Cheng, A.; Hsu, H.M.; Chao, S.J.; Lin, K.L. Experimental study on properties of pervious concrete made with recycled aggregate. Int. J. Pavement Res. Technol. 2011, 4, 104. [CrossRef]

121. Ravindrarajah, R.S.; Neo, H.W.; Lai, J.E. Performance of pervious recycled aggregate concrete with reduced cement content. In Proceedings of the International Conference on Structural Engineering, Construction and Management, Kandy, Central, Sri Lanka, 16-18 December 2011.

122. Suganthan, J.; Vignesh, K.; Sudhakar, A.; Ashraf, S. An Experimental Investigation on Pervious Concrete by Using Furnace Slag and Recycled Coarse Aggregate. SSRG Int. J. Civ. Eng. 2017, ICETM-2017, 108-113.

123. Silva, R.V.; de Brito, J.; Dhir, R.K. Properties and composition of recycled aggregates from construction and demolition waste suitable for concrete production. Constr. Build. Mater. 2014, 65, 201-217. [CrossRef]

124. Hamad, B.S.; Dawi, A.H. Sustainable normal and high strength recycled aggregate concretes using crushed tested cylinders as coarse aggregates. Case Stud. Constr. Mater. 2017, 7, 228-239. [CrossRef]

125. Duan, J.; Asteris, P.G.; Nguyen, H.; Bui, X.N.; Moayedi, H. A novel artificial intelligence technique to predict compressive strength of recycled aggregate concrete using ICA-XGBoost model. Eng. Comput. 2020, 1-18. [CrossRef]

126. Aslani, F.; Ma, G.; Wan, D.L.Y.; Muselin, G. Development of high-performance self-compacting concrete using waste recycled concrete aggregates and rubber granules. J. Clean. Prod. 2018, 182, 553-566. [CrossRef]

127. Seethapathi, M.; Senthilkumar, S.R.R.; Chinnaraju, K. Experimental study on high performance selfcompacting concrete using recycled aggregate. J. Theor. Appl. Inf. Technol. 2014, 67, 84-90.

128. Nitesh, K.J.N.S.; Rao, S.V.; Kumar, P.R. An experimental investigation on torsional behaviour of recycled aggregate based steel fiber reinforced self compacting concrete. J. Build. Eng. 2019, 22, 242-251. [CrossRef]

129. Bartolacci, F.; Paolini, A.; Quaranta, A.G.; Soverchia, M. Assessing factors that influence waste management financial sustainability. Waste Manag. 2018, 79, 571-579. [CrossRef]

130. di Maria, A.; Eyckmans, J.; van Acker, K. Downcycling versus recycling of construction and demolition waste: Combining LCA and LCC to support sustainable policy making. Waste Manag. 2018, 75, 3-21. [CrossRef] [PubMed] 
131. Ding, Z.; Yi, G.; Tam, V.W.Y.; Huang, T. A system dynamics-based environmental performance simulation of construction waste reduction management in China. Waste Manag. 2016, 51, 130-141. [CrossRef]

132. Fraile-Garcia, E.; Ferreiro-Cabello, J.; López-Ochoa, L.M.; López-González, L.M. Study of the technical feasibility of increasing the amount of recycled concrete waste used in ready-mix concrete production. Materials 2017, 10, 817. [CrossRef] [PubMed]

133. Durdyev, S.; Omarov, M.; Ismail, S. Causes of delay in residential construction projects in Cambodia. Cogent Eng. 2017, 4, 1291117. [CrossRef]

134. Du, Z.; Lin, B. Analysis of carbon emissions reduction of China's metallurgical industry. J. Clean. Prod. 2018, 176, 1177-1184. [CrossRef]

135. Menegaki, M.; Damigos, D. A review on current situation and challenges of construction and demolition waste management. Curr. Opin. Green Sustain. Chem. 2018, 13, 8-15. [CrossRef]

136. Jacintho, Ana Elisabete Paganelli Guimarães de Avila, Ivanny Soares Gomes Cavaliere, Lia Lorena Pimentel, and Nádia Cazarim Silva Forti. Modulus and Strength of Concretes with Alternative Materials. Materials 2020, 13, 4378. [CrossRef]

137. Elhakam, A.A.; Mohamed, A.E.; Awad, E. Influence of self-healing, mixing method and adding silica fume on mechanical properties of recycled aggregates concrete. Constr. Build. Mater. 2012, 35, 421-427. [CrossRef]

138. Ma, J.; Sun, D.; Pang, Q.; Sun, G.; Hu, M.; Lu, T. Potential of recycled concrete aggregate pretreated with waste cooking oil residue for hot mix asphalt. J. Clean. Prod. 2019, 221, 469-479. [CrossRef]

139. Cabral, A.E.B.; Schalch, V.; Molin, D.C.C.D.; Ribeiro, J.L.D. Mechanical properties modeling of recycled aggregate concrete. Constr Build. Mater. 2010, 24, 421-430. [CrossRef]

140. Yang, S. Effect of different types of recycled concrete aggregates on equivalent concrete strength and drying shrinkage properties. Appl. Sci. 2018, 8, 2190. [CrossRef]

141. Omary, S.; Ghorbel, E.; Wardeh, G. Relationships between recycled concrete aggregates characteristics and recycled aggregates concretes properties. Constr. Build. Mater. 2016, 108, 163-174. [CrossRef]

142. Deakins, D.; Bensemann, J.O. Achieving Innovation in a Lean Environment: How Innovative Small Firms Overcome Resource Constraints. Int. J. Innov. Manag. 2019, 23, 1950037. [CrossRef]

143. Jin, R.; Li, B.; Zhou, T.; Wanatowski, D.; Piroozfar, P. An empirical study of perceptions towards construction and demolition waste recycling and reuse in China. Resour. Conserv. Recycl. 2017, 126, 86-98. [CrossRef]

144. Dhir, R.K.; de Brito, J.; Silva, R.V.; Lye, C.Q. Recycled Aggregate Concrete: Durability Properties. Sustain. Constr. Mater. 2019, 365-418. [CrossRef]

145. Ozbakkaloglu, T.; Gholampour, A.; Xie, T. Mechanical and Durability Properties of Recycled Aggregate Concrete: Effect of Recycled Aggregate Properties and Content. J. Mater. Civ. Eng. 2018, 30, 04017275. [CrossRef]

146. Jo, B.W.; Park, S.K.; Park, J.C. Mechanical properties of polymer concrete made with recycled PET and recycled concrete aggregates. Constr. Build. Mater. 2008, 22, 2281-2291. [CrossRef]

147. Júnior, N.S.A.; Silva, G.A.O.; Dias, C.M.R.; Ribeiro, D.V. Concrete containing recycled aggregates: Estimated lifetime using chloride migration test. Constr. Build. Mater. 2019, 222, 108-118. [CrossRef]

148. Meneses, E.J.; Gaussens, M.; Jakobsen, C.; Mikkelsen, P.S.; Grum, M.; Vezzaro, L. Coordinating rule-based and system-wide model predictive control strategies to reduce storage expansion of combined urban drainage systems: The case study of Lundtofte, Denmark. Water 2018, 10, 76. [CrossRef]

149. Jain, J.A.; Olek, J.; Verian, K.P.; Whiting, N. Chloride penetration resistance of concrete mixtures with recycled concrete aggregates. In Brittle Matrix Composites 10; Woodhead Publishing: Cambridge, UK, 2012; pp. 377-386.

150. Kou, S.C.; Poon, C.S.; Wan, H.W. Properties of concrete prepared with low-grade recycled aggregates. Constr. Build. Mater. 2012, 36, 881-889. [CrossRef]

151. Silva, R.V.; de Brito, J.; Neves, R.; Dhir, R. Prediction of chloride ion penetration of recycled aggregate concrete. Mater. Res. 2015, 18, 427-440. [CrossRef]

152. Kou, S.C.; Poon, C.S.; Chan, D. Influence of fly ash as a cement addition on the hardened properties of recycled aggregate concrete. Mater. Struct. Constr. 2008, 41, 1191-1201. [CrossRef]

153. O’Donnell, B.T.; Ives, C.J.; Mohiuddin, O.A.; Bunnell, B.A. Beyond the Present Constraints That Prevent a Wide Spread of Tissue Engineering and Regenerative Medicine Approaches. Front. Bioeng. Biotechnol. 2019, 7, 95. [CrossRef]

154. Singh, N.; Singh, S.P. Carbonation and electrical resistance of self compacting concrete made with recycled concrete aggregates and metakaolin. Constr. Build. Mater. 2016, 121, 400-409. [CrossRef]

155. Levy, S.M.; Helene, P. Durability of recycled aggregates concrete: A safe way to sustainable development. Cem. Concr. Res. 2004, 34, 1975-1980. [CrossRef]

156. Grilli, A.; Bocci, M.; Tarantino, A.M. Experimental investigation on fibre-reinforced cement-treated materials using reclaimed asphalt. Constr. Build. Mater. 2013, 38, 491-496. [CrossRef]

157. Peng, Z.; Shi, C.; Shi, Z.; Lu, B.; Wan, S.; Zhang, Z.; Chang, J.; Zhang, T. Alkali-aggregate reaction in recycled aggregate concrete. J. Clean. Prod. 2020, 255, 120238. [CrossRef]

158. Chi, M. Effects of dosage of alkali-activated solution and curing conditions on the properties and durability of alkali-activated slag concrete. Constr. Build. Mater. 2012, 35, 240-245. [CrossRef]

159. Bogas, J.A.; de Brito, J.; Ramos, D. Freeze-thaw resistance of concrete produced with fine recycled concrete aggregates. J. Clean. Prod. 2016, 115, 294-306. [CrossRef] 
160. Richardson, A.; Coventry, K.; Bacon, J. Freeze/thaw durability of concrete with recycled demolition aggregate compared to virgin aggregate concrete. J. Clean. Prod. 2011, 19, 272-277. [CrossRef]

161. Topçu, I.B.; Şengel, S. Properties of concretes produced with waste concrete aggregate. Cem. Concr. Res. 2004, 34, 1307-1312. [CrossRef]

162. Tuyan, M.; Mardani-Aghabaglou, A.; Ramyar, K. Freeze-thaw resistance, mechanical and transport properties of self-consolidating concrete incorporating coarse recycled concrete aggregate. Mater. Des. 2014, 53, 983-991. [CrossRef]

163. Fonseca, N.; De Brito, J.; Evangelista, L. The influence of curing conditions on the mechanical performance of concrete made with recycled concrete waste. Cem. Concr. Compos. 2011, 33, 637-643. [CrossRef]

164. Mardani-Aghabaglou, A.; Andiç-Çakir, Ö.; Ramyar, K. Freeze-thaw resistance and transport properties of high-volume fly ash roller compacted concrete designed by maximum density method. Cem. Concr. Compos. 2013, 37, 259-266. [CrossRef]

165. Princigallo, A.; van Breugel, K.; Levita, G. Influence of the aggregate on the electrical conductivity of Portland cement concretes. Cem. Concr. Res. 2003, 33, 1755-1763. [CrossRef]

166. Kong, D.; Lei, T.; Zheng, J.; Ma, C.; Jiang, J.; Jiang, J. Effect and mechanism of surface-coating pozzalanics materials around aggregate on properties and ITZ microstructure of recycled aggregate concrete. Constr. Build. Mater. 2010, 24, 701-708. [CrossRef]

167. Zhang, H.; Ji, T.; Zeng, X.; Yang, Z.; Lin, X.; Liang, Y. Mechanical behavior of ultra-high performance concrete (UHPC) using recycled fine aggregate cured under different conditions and the mechanism based on integrated microstructural parameters. Constr. Build. Mater. 2018, 192, 489-507. [CrossRef]

168. Wang, R.; Yu, N.; Li, Y. Methods for improving the microstructure of recycled concrete aggregate: A review. Constr. Build. Mater. 2020, 242, 118164. [CrossRef]

169. Assia, D. Effect of recycled coarse aggregate on the new interfacial transition zone concrete. Constr. Build. Mater. 2018, 190, 1023-1033. [CrossRef]

170. Bentz, D.P. Influence of internal curing using lightweight aggregates on interfacial transition zone percolation and chloride ingress in mortars. Cem. Concr. Compos. 2009, 31, 285-289. [CrossRef]

171. Sadek, D.M.; El-Attar, M.M. Development of high-performance green concrete using demolition and industrial wastes for sustainable construction. J. Am. Sci. 2012, 8, 120-131.

172. Babu, V.S.; Mullick, A.K.; Jain, K.K.; Singh, P.K. Strength and durability characteristics of high-strength concrete with recycled aggregate-influence of processing. J. Sustain. Cem. Mater. 2014, 4, 54-71. [CrossRef]

173. Xuan, D.; Zhan, B.; Poon, C.S. Assessment of mechanical properties of concrete incorporating carbonated recycled concrete aggregates. Cem. Concr. Compos. 2016, 65, 67-74. [CrossRef]

174. Zhan, B.J.; Xuan, D.X.; Poon, C.S. Enhancement of recycled aggregate properties by accelerated CO2 curing coupled with limewater soaking process. Cem. Concr. Compos. 2018, 89, 230-237. [CrossRef]

175. Kazmi, S.M.S.; Munir, M.J.; Wu, Y.F.; Patnaikuni, I.; Zhou, Y.; Xing, F. Influence of different treatment methods on the mechanical behavior of recycled aggregate concrete: A comparative study. Cem. Concr. Compos. 2019, 104, 103398. [CrossRef]

176. Wang, L.; Wang, J.; Qian, X.; Chen, P.; Xu, Y.; Guo, J. An environmentally friendly method to improve the quality of recycled concrete aggregates. Constr. Build. Mater. 2017, 144, 432-441. [CrossRef]

177. Tam, V.W.Y.; Tam, C.M.; Le, K.N. Removal of cement mortar remains from recycled aggregate using pre-soaking approaches. Resour. Conserv. Recycl. 2007, 50, 82-101. [CrossRef]

178. Wijayasundara, M.; Mendis, P.; Zhang, L.; Sofi, M. Financial assessment of manufacturing recycled aggregate concrete in ready-mix concrete plants. Resour. Conserv. Recycl. 2016, 109, 187-201. [CrossRef] 